\title{
Low membrane fluidity triggers lipid phase separation and protein segregation in vivo
}

Marvin Gohrbandt ${ }^{\mathrm{a}}$, André Lipski ${ }^{\mathrm{b}}$, Zunera Baig ${ }^{\mathrm{c}}$, Stefan Walter ${ }^{\mathrm{a}}$, Rainer Kurre ${ }^{\mathrm{d}}$, Henrik Strahlc,", and Gabriele Deckers-Hebestreit ${ }^{\mathrm{a}, *}$

${ }^{a}$ Mikrobiologie, Fachbereich Biologie/Chemie, Universität Osnabrück, Osnabrück, Germany

bLebensmittelmikrobiologie und -hygiene, Institut für Ernährungs- und Lebensmittelwissenschaften, Rheinische Friedrich-Wilhelms-Universität Bonn, Bonn, Germany

${ }^{c}$ Centre for Bacterial Cell Biology, Biosciences Institute, Faculty of Medical Sciences, Newcastle University, Newcastle upon Tyne, United Kingdom

${ }^{\mathrm{d} C e n t e r}$ of Cellular Nanoanalytics, Integrated Bioimaging Facility, Universität Osnabrück, Osnabrück, Germany

\section{*Correspondence:}

Gabriele Deckers-Hebestreit (deckers-hebestreit@biologie.uni-osnabrueck.de)

Henrik Strahl (h.strahl@ncl.ac.uk) 


\section{Summary}

Important physicochemical properties of cell membranes such as fluidity sensitively depend on fluctuating environmental factors including temperature, $\mathrm{pH}$ or diet. To counteract these disturbances, living cells universally adapt their lipid composition in return. In contrast to eukaryotic cells, bacteria tolerate surprisingly drastic changes in their lipid composition while retaining viability, thus making them a more tractable model to study this process. Using the model organisms Escherichia coli and Bacillus subtilis, which regulate their membrane fluidity with different fatty acid types, we show here that inadequate membrane fluidity interferes with essential cellular processes such as morphogenesis and maintenance of membrane potential, and triggers large-scale lipid phase separation that drives protein segregation into the fluid phase. These findings illustrate why lipid homeostasis is such a critical cellular process. Finally, our results provide direct in vivo support for current in vitro and in silico models regarding lipid phase separation and associated protein segregation.

Keywords: Lipid phase separation, lipid domains, protein partitioning, membrane fluidity, homeoviscous adaptation, Escherichia coli, Bacillus subtilis, WALP, $\mathrm{F}_{\mathrm{O}} \mathrm{F}_{1}$ ATP synthase 


\section{Introduction}

Biological membranes are complex arrangements predominately composed of lipids and both integral and surface-attached proteins (Nicolson, 2014). The primordial function of biological membranes was likely to act as a simple, semipermeable diffusion barrier separating the cell from its environment, and genomes from each other (Chen and Walde, 2010). Later, membranes and membrane proteins evolved to fulfill a multitude of cellular functions such as transport, respiration, and morphogenesis. Since the physicochemical state of biological membranes is highly sensitive to changes in the environment including temperature, osmolarity, salinity or pH (Ernst et al., 2016; Hazel, 1995), careful homeostatic regulation of key membrane parameters such as thickness or fluidity is vital for cell function (Ernst et al., 2016; Harayama and Riezman, 2018; Levental et al., 2018; Parsons and Rock, 2013; Silhavy et al., 2010).

Arguably, the best studied membrane-adaptive process is homeoviscous adaptation that strives to maintain membrane fluidity upon changes in temperature (Ernst et al., 2018; Ernst et al., 2016; Hazel, 1995; Parsons and Rock, 2013). With increasing temperature, lipid bilayers exhibit reduced head group packing, increased fatty acid disorder, and increased rotational and lateral diffusion; four membrane parameters commonly grouped under the umbrella-term "membrane fluidity" (Chapman, 1975; Heimburg, 2007). All living organisms maintain membrane fluidity in a range optimally supporting vital membrane functions by actively adapting their lipid composition. Most commonly, this is achieved by altering the content of lipids carrying fluidity-promoting unsaturated fatty acids (UFA) and fluidityreducing saturated fatty acids (SFA), respectively, thereby counteracting shifts in membrane fluidity (Ernst et al., 2016; Parsons and Rock, 2013).

While adaptive changes in lipid fatty acid composition as well as the regulatory processes involved are increasingly well characterized (Cybulski et al., 2010; Ernst et al., 2018), the cellular consequences of inadequate membrane fluidity are significantly less well understood. Sufficiently high membrane fluidity has been implicated in promoting folding, catalytic activity, and diffusion of membrane proteins (Andersen and Koeppe, 2007; Lee, 2004). Too high membrane fluidity, in turn, has been shown to increase proton permeability in vitro (Rossignol et al., 1982; van de Vossenberg et al., 1999), thus potentially hampering with efficient ion homeostasis and energy conservation (Valentine, 2007). Comprehensive in vivo studies, however, have been difficult due to experimental challenges associated with modifying the fatty acid composition and, thus, membrane fluidity directly in growing cells. Consequently, our understanding of the behavior of biological membranes upon changing fluidity is predominately based on in vitro and in silico studies with simplified model lipids, or in vitro studies with either natural lipid extracts or isolated membranes (Baumgart et al., 2007; Nickels et al., 2017; Schäfer et al., 2011).

One of the fascinating properties of lipids is their ability to undergo phase transitions between distinct configurations that differ in terms of ability to form bilayers, membrane thickness, and degree of lipid packing (Chapman, 1975). The biologically relevant, bilayer-forming lipid phases are: $(i)$ the 
liquid-disordered phase characterized by low packing density and high diffusion rates that forms the regular state of biological membranes, (ii) the more ordered, cholesterol/hopanoid-dependent liquidordered phase found in biological membranes in form of lipid rafts, and (iii) the gel phase characterized by dense lipid packing with little lateral or rotational diffusion, which is generally assumed to be absent in biologically active membranes (Schmid, 2017; Veatch, 2007). In fact, the temperature associated with gel phase formation has been postulated to define the lower end of the temperature range able to support vital cell functions (Burns et al., 2017; Drobnis et al., 1993; Ghetler et al., 2005). At last, the lipid phases can co-exist, resulting in separated membrane areas exhibiting distinctly different composition and characteristics (Baumgart et al., 2007; Elson et al., 2010; Heberle and Feigenson, 2011). This principal mechanism of lipid domain formation is best studied in the context of lipid rafts (Lingwood and Simons, 2010).

While in vitro and in silico approaches with simplified lipid models have provided detailed insights into the complex physicochemical behavior of lipid bilayers, testing the formed hypotheses and models in the context of protein-rich biological membranes is now crucial. Bacteria tolerate surprisingly drastic changes in their lipid composition and only possess one or two membrane layers as part of their cell envelope. Consequently, bacteria are both a suitable and a more tractable model to study the fundamental biological process linked to membrane fluidity and phase separation in vivo.

We analyzed the biological importance of membrane homeoviscous adaptation in Escherichia coli (phylum Proteobacteria) and Bacillus subtilis (phylum Firmicutes), respectively. These organisms were chosen due to their prominence as Gram-negative and Gram-positive model organisms, and the different archetypes of membrane fatty acid composition (straight vs. branched chain fatty acids) they represent. We have established protocols that allow the fatty acid composition of both organisms to be progressively altered and the cellular consequences to be directly monitored in growing cells. This approach allowed us to address three central questions linked to homeostatic regulation of membrane composition and fluidity: $(i)$ what are the cellular consequences of an inadequate level of membrane fluidity that necessitate the extensive and conserved homeostatic regulatory processes, (ii) how do changes in lipid fatty acid composition translate to changes in membrane fluidity of living cells, and (iii) what is the lipid phase behavior in living cells with protein-crowded membranes and intact lipid domain organization?

Our results demonstrate that too low membrane fluidity results in growth arrest in both organisms, which is accompanied by severe disturbances of the cell morphogenesis and ion homeostasis. Furthermore, too low fluidity triggers a striking, large-scale lipid phase separation into liquid-disordered and gel phase membranes, accompanied by segregation of otherwise disperse membrane proteins such as ATP synthase and glucose permease. Our results are fully consistent with the general, albeit so far not directly tested notion that phase separation between liquid-disordered and gel state membranes is associated with loss of essential membrane functions, thereby limiting the range of membrane fluidity able to support life. At last, our findings demonstrating that gel-liquid phase separation and associated 
membrane protein segregation indeed occurs in protein-crowded, native plasma membranes of living cells, are fully consistent with the comparable phenomena observed in in vitro and in silico model systems (Baumgart et al., 2007; Domanski et al., 2012; Elson et al., 2010; Schafer et al., 2011; Veatch and Keller, 2002). Thus, the results provide strong in vivo support for the general validity of the respective models.

\section{Results}

\section{Depletion of branched chain fatty acids in $B$. subtilis}

In order to disrupt the native lipid homeostasis of B. subtilis and to enable the fatty acid composition to be modified, we constructed a strain carrying deletions of the $b k d$ operon and the des gene. The $b k d$ operon encodes enzymes catalyzing the conversion of branched chain amino acids into intermediates for branched chain fatty acid (BCFA) synthesis (Debarbouille et al., 1999). The lack of this activity can be complemented by supplementation with precursors such as 2-methylbutyric acid (MB) and isobutyric acid (IB) (Boudreaux et al., 1981; Kaneda, 1977; Willecke and Pardee, 1971) resulting in synthesis of precursor-specific fatty acid species. This provides the experimental means to control the lipid iso- and anteiso-BCFA composition, which is normally responsible for the homeostatic adaptation of membrane fluidity in response to environmental changes (Diomandé et al., 2015; Klein et al., 1999). In addition, the strain is deficient for the lipid desaturase Des, which enables rapid adaptation of membrane fluidity by converting SFA as well as BCFA directly into fluidity-promoting UFAs by inserting a cis-double bond at $\Delta 5$-position (Aguilar et al., 1998). In the remaining text, we will label this B. subtilis strain " $\Delta b k d "$ for simplicity.

We first compared the growth of B. subtilis 168 (Barbe et al., 2009) designated here as wild type (WT) and $\Delta b k d$ cells at $37^{\circ} \mathrm{C}$ upon supplementation with BCFA precursors MB or IB (Figure 1A). While the precursors had little impact on growth of WT cells, the auxotrophic $\Delta b k d$ strain only grew in the presence of either of the precursors. Corresponding fatty acid analyses revealed large shifts in the composition of the $\Delta b k d$ strain depending on the supplied precursor (Figures $1 \mathrm{~B}$ and $\mathrm{S} 1 \mathrm{~A}$ ). As expected, cells supplemented with MB exhibited a high content (77\%) of anteiso-BCFAs and a low content of SFAs or iso-BCFAs. Cells grown with IB, in turn, showed a correspondingly high content of iso-BCFAs (77\%). To obtain cells depleted for both BCFA types, cells were grown initially in the presence of IB, followed by wash, and further incubation in precursor-free (PF) medium. This precursor depletion leads to growth arrest after about 90 min (Figure S1A), corresponding to an accumulated SFA content of $\sim 50$ $\%$ at cost of iso-BCFAs (Figure 1B).

Analyses of $\Delta b k d$ cells incubated at different growth temperatures and with different BCFA precursors (Figures 1C and $\mathrm{S1B}$ ) indicated that only $\mathrm{MB}$, the precursor for anteiso-BCFAs, is capable for supporting robust growth at low temperatures $\left(22^{\circ} \mathrm{C}\right)$. At $30^{\circ} \mathrm{C}$ and $37^{\circ} \mathrm{C}$, cell growth was comparable in the presence of either $\mathrm{MB}$ or $\mathrm{IB}$, while no growth was observed in the absence of precursors, thus demonstrating that a high level of BCFAs is essential under these growth conditions. 
At high growth temperatures $\left(45^{\circ} \mathrm{C}\right)$, the $\Delta b k d$ strain could grow at low dilutions even in the absence of BCFA precursors. Crucially, both $B$. subtilis WT and $\Delta$ des single deletion strain exhibited robust growth across the whole temperature range tested (Figure S1B). For these reasons, we chose the growth behavior at $37^{\circ} \mathrm{C}$, obtained through supplementation with IB, as the viable growth condition for $B$. subtilis $\Delta b k d$. In the following chapters, the cellular consequences of BCFA depletion are compared against this reference.
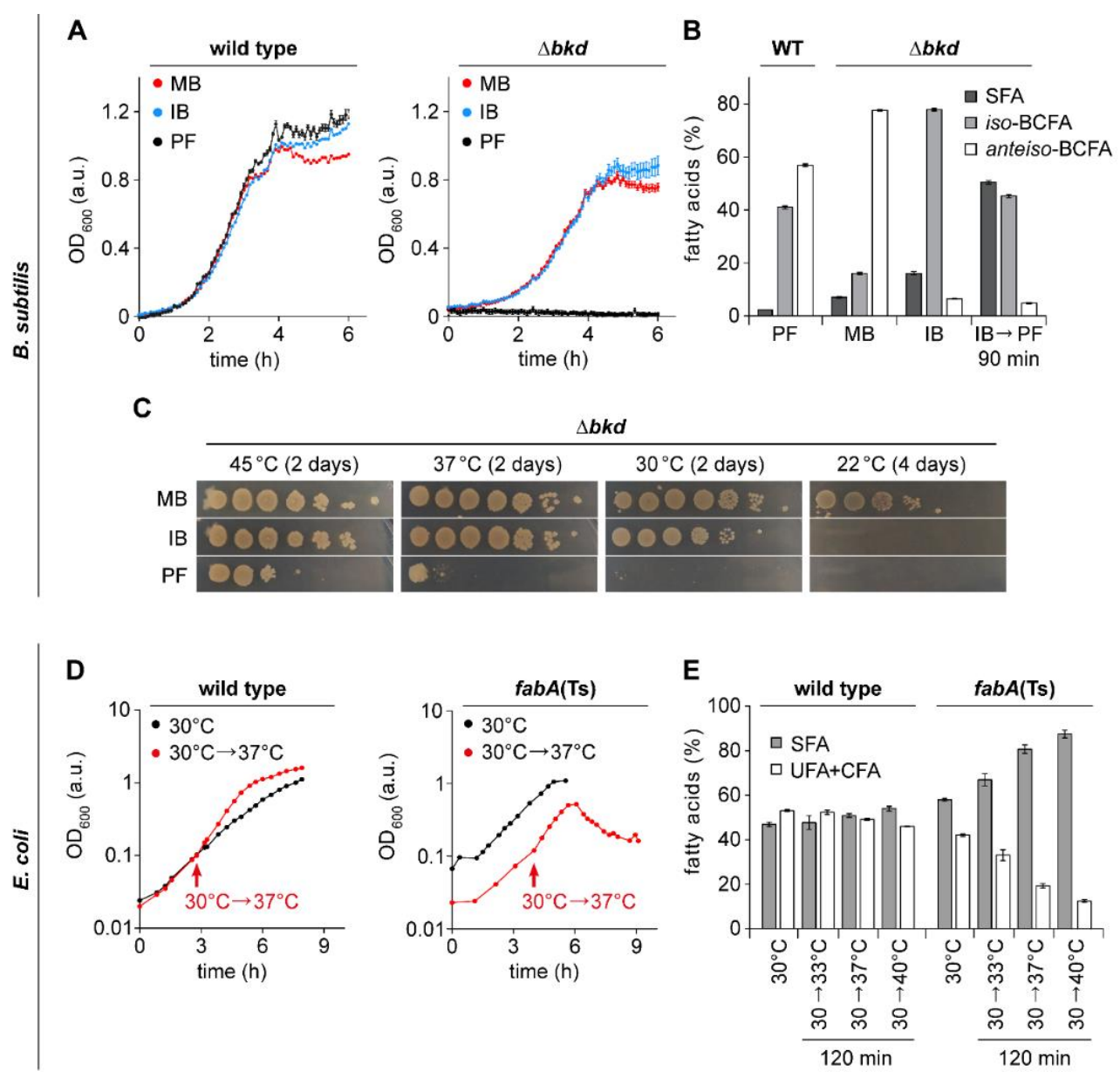

Figure 1. Membrane fatty acid composition-dependent growth of B. subtilis and E. coli. (A) Growth of $B$. subtilis WT and fatty acid precursor-auxotrophic $\Delta b k d$ cells in medium supplemented with precursor MB or IB, or grown precursor-free (PF). Mean \pm SD of technical triplicates. (B) Fatty acid composition of $B$. subtilis WT cells grown in PF medium, and $\Delta b k d$ grown with $\mathrm{MB}, \mathrm{IB}$, or depleted for precursors for $90 \mathrm{~min}(\mathrm{IB} \rightarrow \mathrm{PF})$. For detailed analyses, see Figure S1A. Mean \pm SD of biological triplicates. (C) Temperature-dependent growth of B. subtilis $\Delta b k d$ on solid medium in serial 10-fold dilutions. For comparison between WT, $\Delta d e s$, and $\Delta b k d \Delta d e s$ cells, see Figure S1B. Representative of three independent repeats. (D) Temperature-dependent growth behavior of E. coli WT and $f a b A(\mathrm{Ts})$, including a shift from $30^{\circ} \mathrm{C}$ to $37^{\circ} \mathrm{C}$ as non-permissive temperature of $f a b A(\mathrm{Ts})$. Representative of three independent repeats. (E) Fatty acid composition of E. coli WT and $f a b A(\mathrm{Ts})$ cells grown at $30^{\circ} \mathrm{C}$, and shifted to different temperatures for $2 \mathrm{~h}$. For detailed analyses, see Figure S2. Mean \pm SD of biological triplicates. Strains used: (A-C) B. subtilis 168, HS527; (D, E) E. coli MG1, MG4 (these strains additionally encode fluorescent ATP synthase $\left(\mathrm{F}_{\mathrm{O}} \mathrm{F}_{1} a\right.$-mNG)). 


\section{Depletion of unsaturated fatty acids in $E$. coli}

In contrast to B. subtilis, membrane fluidity in E. coli is modulated by unsaturated fatty acids (UFAs) (Marr and Ingraham, 1962; Sinensky, 1974). While synthesis of UFAs is essential in E. coli, a temperature-sensitive $f a b F f a b A(\mathrm{Ts})$ mutant, in which a shift to non-permissive growth temperatures leads to UFA depletion, has been isolated (Cronan and Gelmann, 1973). DNA sequencing of $f a b F$ and fabA from this rather old isolate revealed that FabF ( $\beta$-ketoacyl-ACP synthase II), which enables the synthesis of fatty acid cis- $\Delta 11-\mathrm{C} 18: 1$ at low temperatures, is non-functional due to S291N and G262S substitutions. FabA ( $\beta$-hydroxyacyl-ACP-dehydratase/isomerase), in contrast, carries a G101D substitution. Based on the structure of the FabA head-to-tail homodimer (Nguyen et al., 2014), G101 is positioned at the border of the dimerization interface. Consequently, the G101D substitution could plausibly cause thermosensitivity by destabilizing the essential dimer structure of FabA at elevated temperatures, thereby provoking the gradual depletion of UFA (Cronan and Gelmann, 1973). Throughout the text, we will label this E. coli strain " $f a b A(T s)$ " for simplicity.

While the growth of $f a b A(\mathrm{Ts})$ at $30^{\circ} \mathrm{C}$ is comparable to E. coli Y-Mel (Rickenberg and Lester, 1955) used here as WT, transfer to non-permissive temperatures such as $37^{\circ} \mathrm{C}$ only supported growth for about $120 \mathrm{~min}$, followed by growth arrest and onset of cell lysis (Figure 1D). Corresponding fatty acid analyses confirmed a strong, temperature-dependent decrease in the UFA content (Figures 1E and S2). In agreement with (Cronan and Gelmann, 1973), a minimal amount of 10-15\% UFAs appeared to be essential to support growth (Figures $1 \mathrm{E}$ and S2A). In comparison, WT cells showed only minor, temperature-dependent changes in fatty acid composition caused by homeoviscous adaptation towards increased SFA content at higher temperatures (Figures 1E and S2B).

\section{Reduced membrane fluidity in cells depleted of unsaturated or branched chain fatty acids}

To confirm that the observed changes in fatty acid composition translate to shifts in in vivo membrane fluidity, we monitored changes in steady-state fluorescence anisotropy of 1,6-diphenyl-1,3,5-hexatriene (DPH), which is sensitive to acyl chain order and, thus, fluidity of lipid bilayers (Lentz, 1993). In good agreement with the corresponding fatty acid profiles, DPH anisotropy measurements with B. subtilis $\Delta b k d$ revealed the highest membrane fluidity for cells with the highest anteiso-BCFA content (Figure 2A). Cells with high iso-BCFA content exhibited membrane fluidity levels slightly lower than those found for WT. These results confirm that anteiso-BCFAs promote higher membrane fluidity than the corresponding iso-forms in vivo; a difference previously based on in vitro evidence only (Lewis and McElhaney, 1985; Lewis et al., 1987). In contrast to the minor changes in fluidity observed between membranes enriched in different BCFA species, the changes observed upon depletion of BCFAs altogether were much more drastic. This depletion, which is accompanied by accumulation of SFAs, resulted in a gradual reduction of membrane fluidity ultimately leading to growth arrest (Figures $2 \mathrm{~A}$ and S1A).

The DPH anisotropy measurements conducted with E. coli followed a similar trend (Figure 2B). 
Both E. coli WT and $f a b A(\mathrm{Ts})$ cells grown at $30^{\circ} \mathrm{C}$ exhibited an expected increase in membrane fluidity upon a shift to $37^{\circ} \mathrm{C}$; a phenomenon that is overtime counteracted by homeoviscous adaptation restoring membrane fluidity closer to pre-shift levels. In contrast to WT cells continuing incubation of $f a b A(T s)$ at $37^{\circ} \mathrm{C}$ resulted in a gradual increase in DPH anisotropy, thus confirming that the depletion of fluiditypromoting fatty acids triggers a substantial reduction of membrane fluidity in E. coli.

In conclusion, the observed changes in fatty acid composition and membrane fluidity are fully consistent for both organisms. This confirms that the established fatty acid depletion procedures allow membrane fluidity to be controllably lowered to a point incapable of supporting growth. In the following chapters, we use this approach to analyze which cellular processes are inhibited by inadequate levels of membrane fluidity with focus on the capacity of the membrane (i) to maintain its essential diffusion barrier functions, (ii) to support membrane-associated cellular machineries responsible for growth and division, and (iii) to support lateral diffusion of membrane proteins.
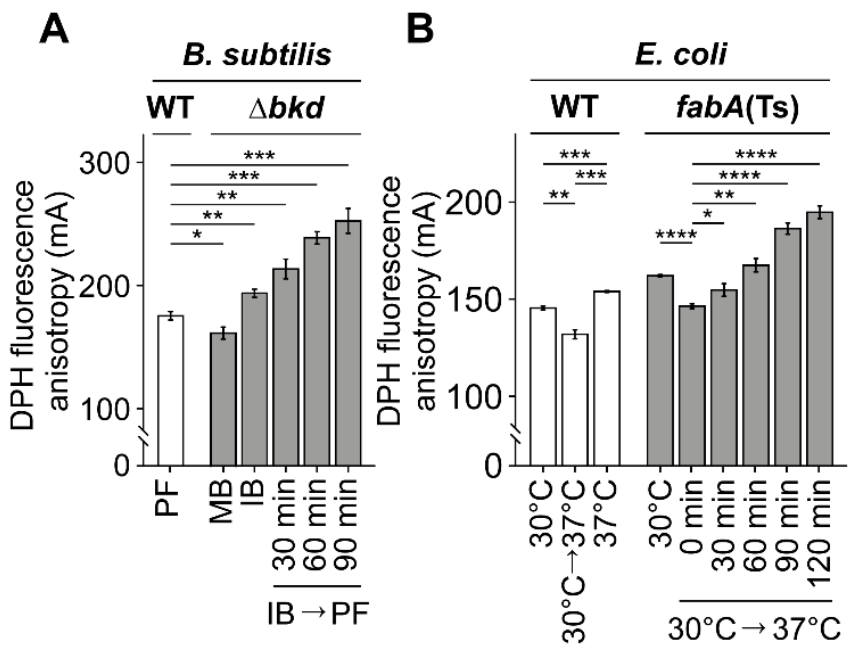

Figure 2. Reduced membrane fluidity in cells depleted for unsaturated or branched chain fatty acids. (A) DPH anisotropy of $B$. subtilis WT or $\Delta b k d$ cells supplemented either with MB, IB, or depleted for precursors for $90 \mathrm{~min}(\mathrm{IB} \rightarrow \mathrm{PF})$ for the times indicated. High DPH anisotropy indicates low membrane fluidity. (B) DPH anisotropy of E. coli WT cells grown steady state at $30^{\circ} \mathrm{C}$ or $37^{\circ} \mathrm{C}$, and cells shifted from $30^{\circ} \mathrm{C}$ to $37^{\circ} \mathrm{C}$, followed by immediate measurement. In addition, DPH anisotropy of fabA(Ts) cells grown steady state at $30^{\circ} \mathrm{C}$ or shifted from $30^{\circ} \mathrm{C}$ to $37^{\circ} \mathrm{C}$ followed by measurement at the times indicated. (A, B) Means \pm SD of technical triplicates, together with P values of an unpaired, twosided t-test. Representative of three independent repeats. Significance was assumed with $* * * * \mathrm{p}<$ $0.0001, * * * \mathrm{p}<0.001, * *<0.01, * \mathrm{p}<0.05$, n.s., not significant. Strains used: (A) B. subtilis 168, HS527; (B) E. coli Y-Mel, UC1098.

\section{Consequences of low membrane fluidity on membrane diffusion barrier function}

The universal prevalence of adaptive mechanisms carefully maintaining membrane fluidity (Hazel, 1995 ) might indicate its importance for maintaining the fundamental membrane barrier function. Indeed, membrane leakage caused by both too high and too low membrane fluidity has been postulated (Antonov et al., 1980; Blicher et al., 2009; Rossignol et al., 1982; van de Vossenberg et al., 1999). To analyze the 
consequences of too low membrane fluidity on membrane leakiness, we used the combination of two fluorescent dyes Sytox Green and $\operatorname{DiSC}_{3}(5)$. Sytox Green is a membrane impermeable, DNAintercalating dye that is commonly used to assess the integrity of bacterial plasma membranes in terms of permeability (Roth et al., 1997). $\operatorname{DiSC}_{3}(5)$ is a voltage-sensitive dye that accumulates in cells with high membrane potential (Te Winkel et al., 2016). Changes in $\mathrm{DiSC}_{3}(5)$ fluorescence therefore indicate changes in either membrane ion conductivity or respiration.
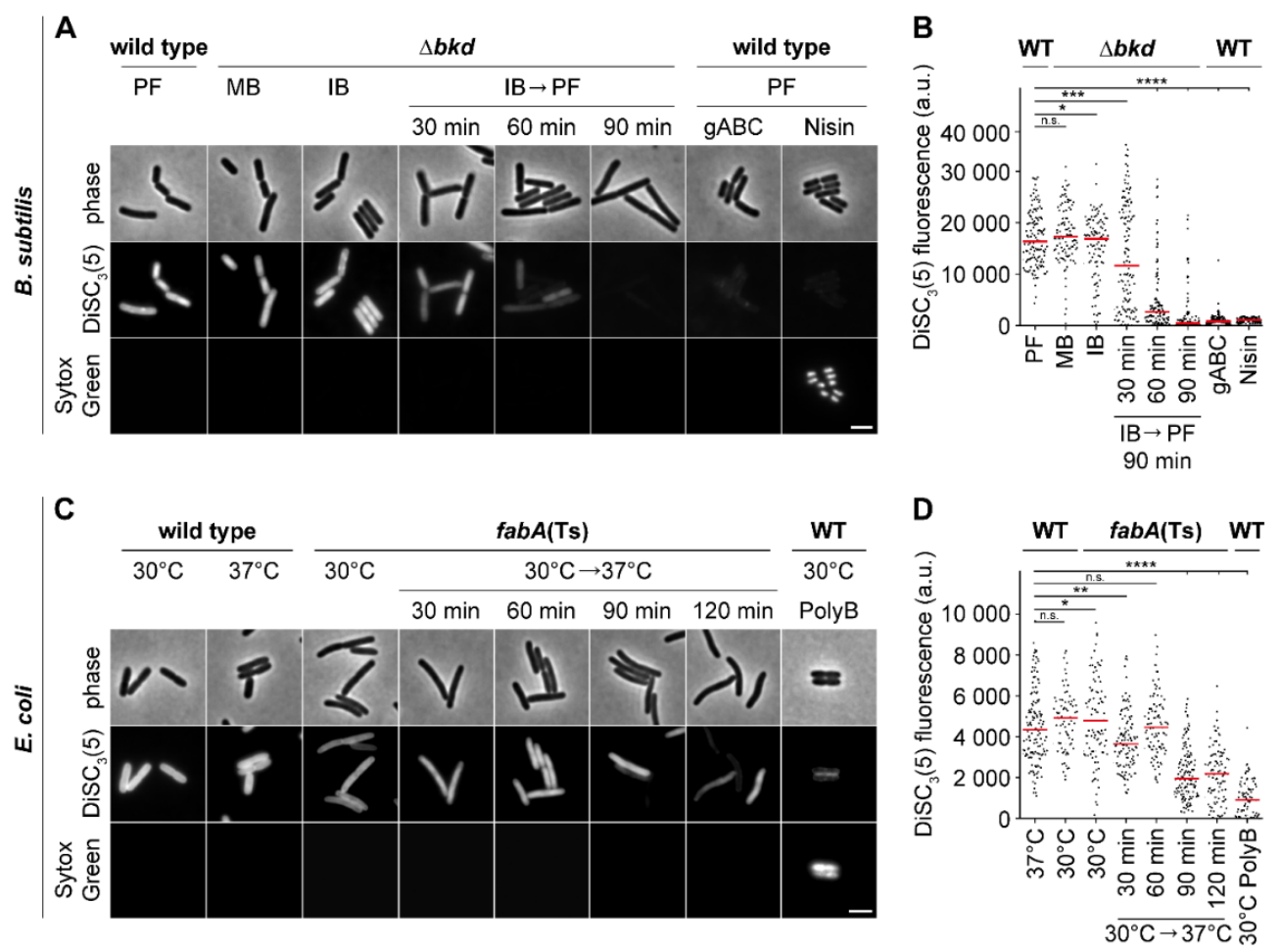

Figure 3. Consequences of low membrane fluidity on membrane diffusion barrier function. (A) Images of $B$. subtilis WT and $\Delta b k d$ cells co-labeled with the membrane potential-sensitive dye $\mathrm{DISC}_{3}(5)$ or the membrane permeability indicator Sytox Green. Membrane properties were assessed for $\Delta b k d$ cells grown with $\mathrm{MB}, \mathrm{IB}$ or IB $\rightarrow \mathrm{PF}$ for the time points indicated. As controls, WT cells were measured in the presence of depolarizing antimicrobial peptide gramicidin $\mathrm{ABC}(\mathrm{gABC})$ or pore-forming lantibiotic Nisin. (B) Quantification of $\operatorname{DISC}_{3}$ (5) fluorescence for cells $(n=100-142)$ depicted in panel A, and the corresponding $\mathrm{P}$ values of an unpaired, two-sided t-test. Median represented by red line. (C) Images of E. coli $\mathrm{WT}$ and $f a b A(\mathrm{Ts})$ cells co-labeled with the same indicator dyes. Membrane properties were assessed for $f a b A(\mathrm{Ts})$ at $30^{\circ} \mathrm{C}$ and upon transfer to non-permissive $37^{\circ} \mathrm{C}$ for the time points indicated. As controls, WT cells were incubated with the pore-forming antibiotic Polymyxin B (PolyB). (D) Quantification of $\operatorname{DISC}_{3}(5)$ fluorescence for cells $(n=76-141)$ depicted in panel C, and the corresponding $\mathrm{P}$ values of an unpaired, two-sided t-test. Significance was assumed with $* * * * \mathrm{p}<0.0001$, *** $\mathrm{p}<0.001$, $* *<0.01, * \mathrm{p}<0.05$, n.s., not significant. (A-D) Representative of three independent repeats. Median represented by red line. Scale bar, $3 \mu \mathrm{m}$. Strains used: (A, B) B. subtilis 168, HS527; (C, D) E. coli YMel, UC1098.

Actively growing B. subtilis $\Delta b k d$ cells, irrespectively of the supplied BCFA precursor, exhibited $\mathrm{DiSC}_{3}(5)$ fluorescence signals comparable to those measured for WT cells (Figures 3A and 3B). This indicates that the corresponding changes in the membrane fatty acid composition and fluidity had 
surprisingly little impact on membrane potential. In contrast, depletion of BCFAs triggered a gradual membrane depolarization that was, in a mild form, already detectable after $30 \mathrm{~min}$. A complete membrane depolarization (Figure 3B) was observed after 90 min coinciding with growth arrest (Figure S1A). Throughout BCFA depletion, however, membranes remained impermeable for Sytox Green (Figure 3A), thus demonstrating that the gradual membrane depolarization was not caused by simple membrane permeabilization. Hence, even the severely BCFA-depleted membranes exhibiting very low membrane fluidity were fully capable of forming a continuous, tight diffusion barrier.

High $\operatorname{DiSC}_{3}(5)$ fluorescence signals and, thus, high membrane potential levels were also observed both for E. coli WT and $f a b A(\mathrm{Ts})$ grown at the permissive temperature of $30^{\circ} \mathrm{C}$ (Figures $3 \mathrm{C}$ and 3D). As in case of BCFA depletion in B. subtilis, also depletion of fluidity-promoting UFA in $E$. coli fabA(Ts) triggered a gradual loss of membrane potential. However, the loss was delayed and never reached complete depolarization (Figure 3D). The lack of Sytox Green staining again revealed that the membranes were not impaired in their general diffusion barrier function (Figure 3C).

In summary, while membrane depolarization is observed as a consequence of too low membrane fluidity in both organisms, the core permeability function of the plasma membrane is not compromised even upon conditions unable to support growth. This is consistent with a more subtle effect of low fluidity on membrane-associated biological processes maintaining ion homeostasis such as respiration.

\section{Consequences of low membrane fluidity on cell morphogenesis}

In rod-shaped bacteria like E. coli and B. subtilis, cell growth and morphogenesis is predominately driven by two membrane-associated multiprotein complexes, the elongasome responsible for envelope expansion and rod shape determination through spatially organized cell wall synthesis (Typas et al., 2012), and the divisome responsible for cytokinesis (Adams and Errington, 2009). The main scaffold proteins for these prominent cellular machineries are the tubulin-homolog FtsZ (Adams and Errington, 2009) and the actin homolog MreB (Shi et al., 2018). To assess the functionality of these key cellular machineries, we followed the localization of GFP fusions to MreB or FtsZ upon depletion of fluiditypromoting fatty acids both in E. coli and B. subtilis. Furthermore, by use of GFP-fused DNA-binding protein $\mathrm{Hu}$ (B. subtilis) (Köhler and Marahiel, 1997) or staining of DNA with intercalating dye DAPI (E. coli), we analyzed the cells for potential defects in chromosome replication and segregation.

In B. subtilis, depletion of BCFAs had no effect on nucleoid prevalence and morphology indicating the presence of largely functional DNA replication, segregation, and compaction mechanisms (Figures 4A and S3A). While no DNA-free cells indicative for defects in DNA replication and segregation were observed in E. coli either, a clear decondensation of the nucleoid was evident at later stages of UFA depletion (Figures 4B and S3B). The cell division machinery, indicated by mid-cell localization of FtsZ, turned out to be surprisingly robust towards changes in membrane fluidity in $B$. subtilis, with only a weakening of the fluorescent mid-cell signal observed upon BCFA depletion (Figures 4A and S3A). In contrast, a clear defect in divisome assembly was observed upon depletion of 
UFA in E. coli (Figures 4B and S3B). An inverse sensitivity was observed for the cell elongation machinery using localization of MreB as proxy. In this case, depletion of BCFA triggered a complete disassembly of the MreB cytoskeleton in B. subtilis (Figures 4A and S3A), whereas the localization of the $E$. coli counterpart was largely unaffected from UFA depletion (Figures 4B and S3B).

In conclusion, very low membrane fluidity incapable to support growth indeed affects membrane-associated cellular machineries responsible for bacterial growth and division.

A

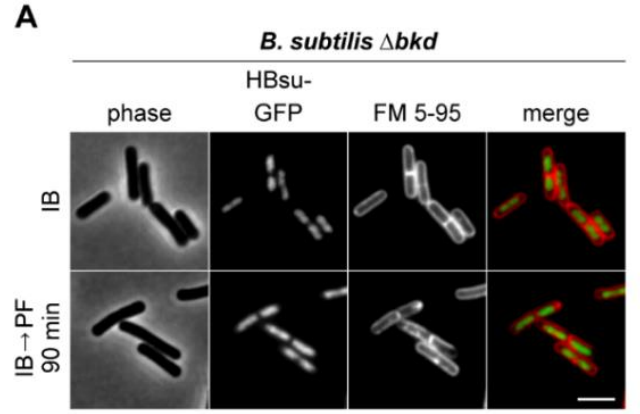

GFP.
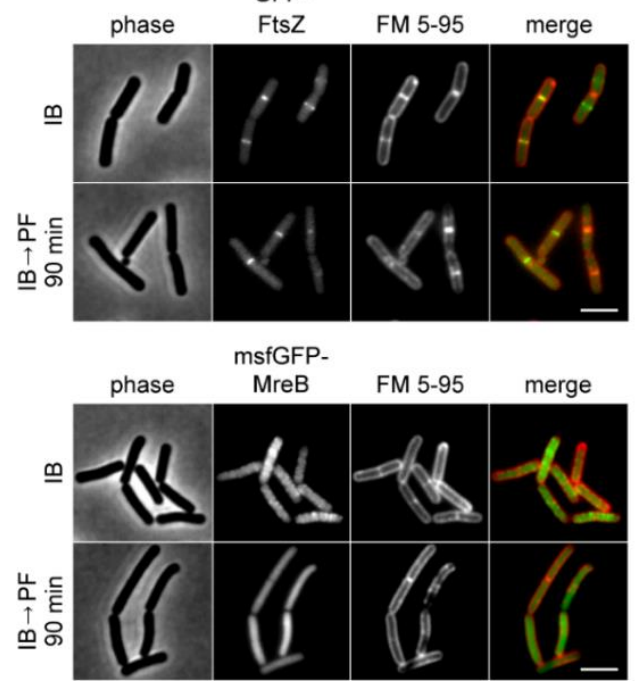

B

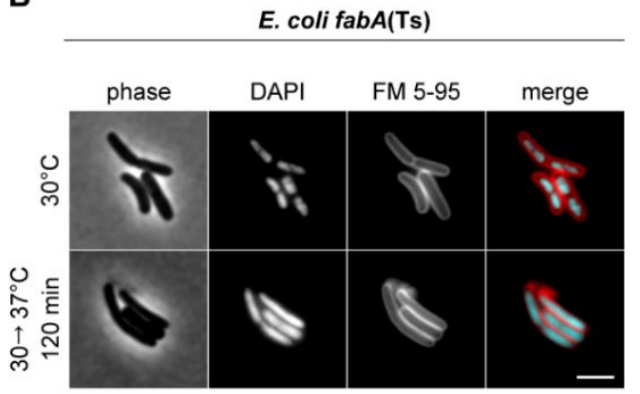

FtsZ-

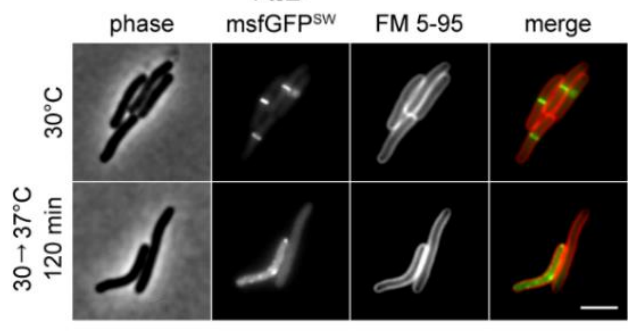

MreB-

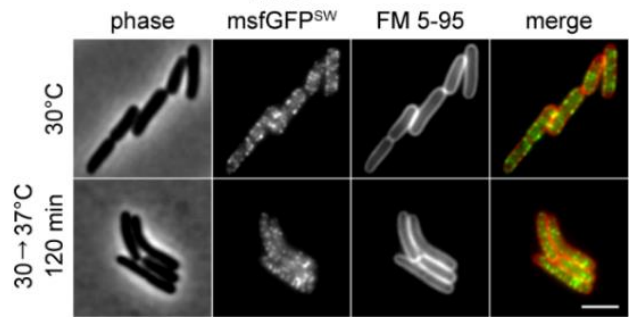

Figure 4. Consequences of low membrane fluidity on cell morphogenesis. (A) Images of B. subtilis $\Delta b k d$ cells stained with membrane dye FM 5-95, and expressing GFP fusions of DNA-binding protein HBsu, cell division protein FtsZ or cell elongation protein MreB. Cells were grown with IB or depleted for precursors for $90 \mathrm{~min}$. (B) Images of E. coli fabA(Ts) cells stained with FM 5-95 for the outer membrane, and with DAPI for DNA, or expressing GFP s sandwich (SW) fusions of FtsZ and MreB, respectively. Cells were grown at $30^{\circ} \mathrm{C}$ or with a temperature shift to $37^{\circ} \mathrm{C}$ for $120 \mathrm{~min}$. (A, B) For further examples and additional time points, see Figure S3. Representative of biological triplicates. Scale bar, $3 \mu \mathrm{m}$. Strains used: (A) B. subtilis HS541, HS548, HS549; (B) E. coli UC1098, BHH500, BHH501.

\section{Consequences of low membrane fluidity on membrane homogeneity}

In the microscopic experiments described above, the cells were stained with the fluorescent dye FM 595. This hydrophobic dye allows visualization of the plasma membrane of B. subtilis (Sharp and Pogliano, 1999), whereas in E. coli the dye stains the outer membrane (Pilizota and Shaevitz, 2012). While no changes in FM 5-95 staining were observed in E. coli cells, the smooth staining observed in 
$\Delta b k d$ cells supplemented with iso-BCFA precursor IB transitioned into a distinctly irregular pattern upon BCFA depletion (Figure 4A). This suggests that the more homogeneous membrane, present under normal growth conditions, segregates into areas with different local physicochemical properties upon low membrane fluidity. This development of membrane irregularities coincides with the growth arrest (Figure 5A and Movie S1).

A B. subtilis $\Delta$ bkd
$\mathrm{IB} \rightarrow \mathrm{PF}$

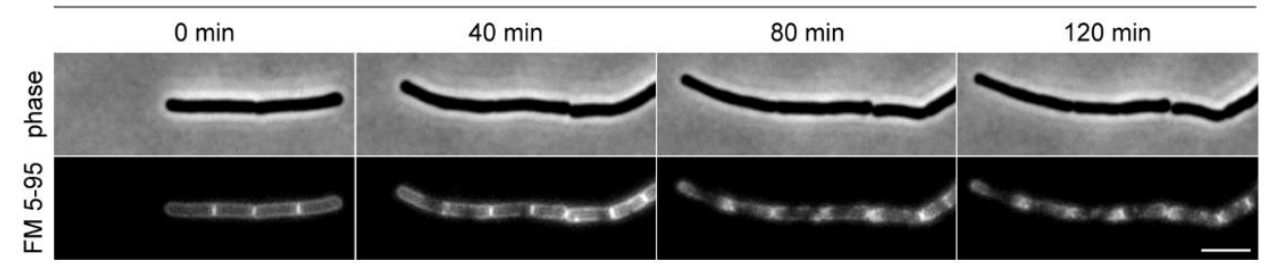

B

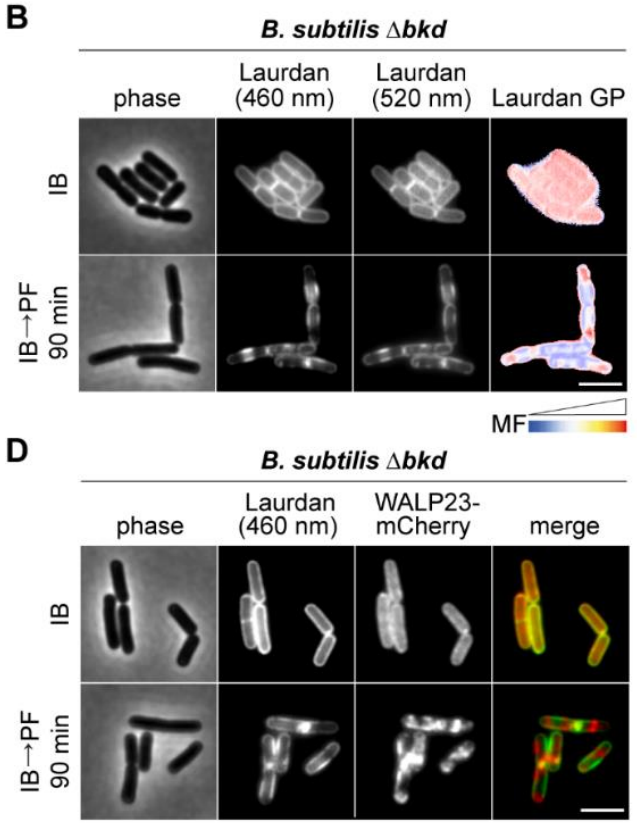
C coli fabA(Ts)

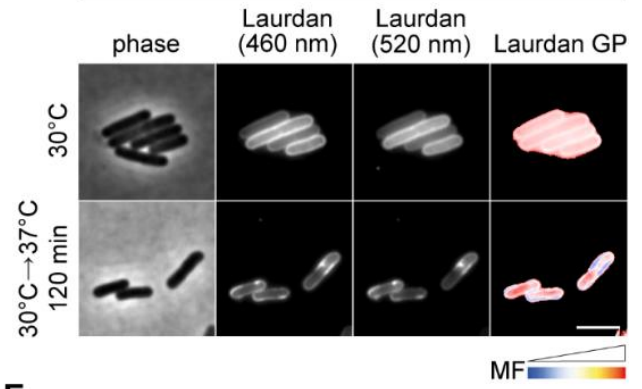

E

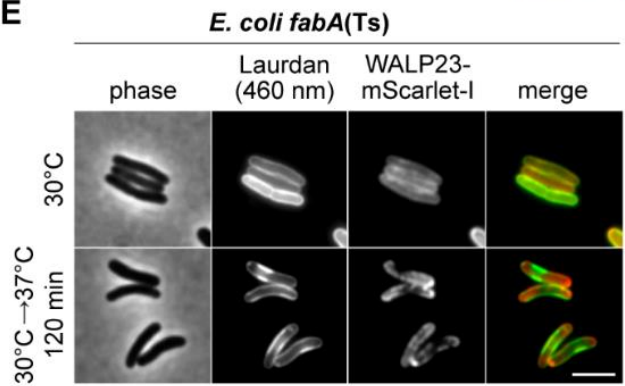

Figure 5. Consequences of low membrane fluidity on membrane homogeneity. (A) Time lapse images of B. subtilis $\Delta b k d$ cells stained with FM 5-95 and grown in PF medium. See Movie S1 for full time lapse. (B, C) Images of B. subtilis $\Delta b k d$ grown with IB or without precursor (IB $\rightarrow \mathrm{PF}$ ), or E. coli $f a b A(\mathrm{Ts})$ grown at $30^{\circ} \mathrm{C}$ or shifted to non-permissive $37^{\circ} \mathrm{C}$. Cells were stained with fluidity-sensitive dye Laurdan and imaged at $460 \mathrm{~nm}, 520 \mathrm{~nm}$, and as the corresponding color-coded Laurdan GP map. MF, membrane fluidity. (D, E) Images of cells grown and stained as in panels B and C, but additionally expressing fluorescent WALP23. For corresponding fluorescence intensity correlations between images, see Figures S4A and S4B. (A-E) Representative of biological triplicates. Scale bar, $3 \mu \mathrm{m}$. Strains used: (A, B) B. subtilis HS527; (C) E. coli UC1098; (D) B. subtilis HS547; (E) E. coli UC1098/pBH501.

In vitro, lipid mixtures of low fluidity undergo phase transition into a more tightly packed gel state. We speculated that the lipid de-mixing observed in B. subtilis (Figures 4A and 5A) could therefore represent large-scale lipid phase separation between gel and liquid-disordered phases. To test this hypothesis, we analyzed the local membrane fluidity of both B. subtilis and E. coli with the fluiditysensitive membrane dye Laurdan. Laurdan exhibits a fluidity-dependent shift in its fluorescence 
emission spectrum, which in turn allows local membrane fluidity to be measured as Laurdan generalized polarization (GP) (Parasassi et al., 1990; Scheinpflug et al., 2017a; Wenzel et al., 2018). Indeed, when B. subtilis and E. coli cells were depleted for fluidity-promoting fatty acids, domain formation associated with local differences in membrane fluidity was observed. In addition, Laurdan also showed a clear preferred accumulation in membrane areas of lower fluidity (Figures 5B and 5C). To verify these findings with an independent method, and to address the common concerns regarding the specificity of chemical dyes in context of lipid domains, we repeated the experiments with cells expressing helical transmembrane peptide WALP23, which has been shown to preferentially accumulate in fluid membrane areas (Ridder et al., 2004; Schäfer et al., 2011; Scheinpflug et al., 2017b). Co-labeling of cells with Laurdan clearly demonstrated that the observed lipid phase separation results in segregation of WALP23 in membrane areas of low Laurdan fluorescence, thus indicating partitioning into the more fluid membrane areas (Figures 5D, 5E, S4A, and S4B). At last, co-staining with FM 5-95 demonstrated that FM 5-95 and WALP23 share the same preference for higher fluidity areas in de-mixed membranes (Figures S4C and S4D). In conclusion, by exhibiting de-mixing into distinct areas of high or low membrane fluidity, the observed in vivo domain formation shares the core characteristic of lipid phase separation between fluid and gel state membranes (Baumgart et al., 2003; Domański et al., 2012; Mostofian et al., 2019).

\section{Partitioning of membrane proteins into fluid domains of phase-separated plasma membranes}

As indicated by effects on WALP23 (Figures 5D, 5E, and S3B), the observed lipid phase separation might have broader consequences on membrane protein localization and segregation. To test this, we focused on E. coli for two reasons. Firstly, the membrane depolarization caused by low membrane fluidity, which itself can affect membrane proteins (Strahl and Hamoen, 2010), is less extensive in $E$. coli than in B. subtilis (Figure 3). Secondly, E. coli does not exhibit depolarization-triggered delocalization of MreB (Figure 4B), which we have previously shown to induce membrane protein clustering (Strahl et al., 2014). As a model protein of choice, we focused on ATP synthase $\left(\mathrm{F}_{\mathrm{O}} \mathrm{F}_{1}\right)$, a polytopic membrane protein complex present in high abundance in the plasma membrane of E. coli $(\mathrm{Li}$ et al., 2014).

In order to visualize the localization of E. coli $\mathrm{F}_{\mathrm{O}} \mathrm{F}_{1}$, we constructed a stable and active fluorescent protein fusion at the $\mathrm{C}$ terminus of the membrane-integral $\mathrm{F}_{\mathrm{O}}-a$ subunit (Figures S5A and $\mathrm{S} 5 \mathrm{~B})$. Upon UFA depletion, $\mathrm{F}_{\mathrm{O}} \mathrm{F}_{1}$ showed clear segregation behavior reminiscent to that observed with WALP23 (Figure 6A and Movie S2). When co-expressed, $\mathrm{F}_{\mathrm{O}} \mathrm{F}_{1}$ and WALP23 showed clear cosegregation into the fluid areas of phase-separated membranes (Figure 6B). This property was also confirmed by co-staining with Laurdan (Figure 6C) showing an anti-correlation of the fluorescent signals (Figures S4E and S4F). 


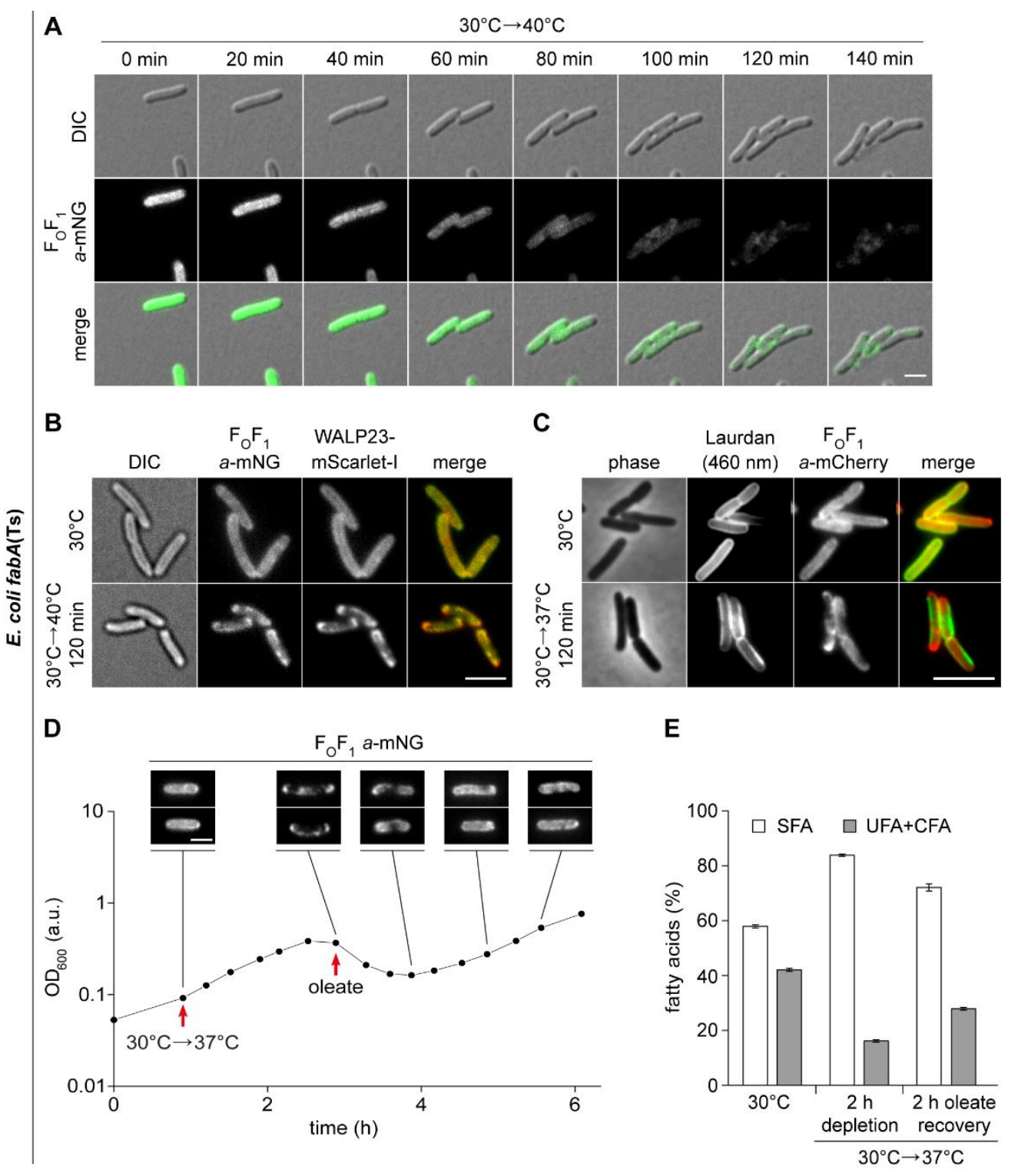

Figure 6. Partitioning of membrane proteins into fluid domains of phase-separated plasma membranes. (A) Time lapse images of E. coli fabA(Ts) cells expressing $\mathrm{F}_{\mathrm{O}} \mathrm{F}_{1} a$-mNG, shifted from $30^{\circ} \mathrm{C}$ to non-permissive $37^{\circ} \mathrm{C}$. See Movie S2 for full time lapse. DIC, differential interference contrast. (B) Images of $f a b A(\mathrm{Ts})$ co-expressing WALP23-mScarlet-I and $\mathrm{F}_{\mathrm{O}} \mathrm{F}_{1} a$-mNG, grown at $30^{\circ} \mathrm{C}$ or shifted to non-permissive $40^{\circ} \mathrm{C}$. For fluorescence intensity correlations, see Figure S4E. (C) Images of $f a b A(\mathrm{Ts})$ expressing $\mathrm{F}_{\mathrm{O}} \mathrm{F}_{1} a$-mNG grown at $30^{\circ} \mathrm{C}$ or shifted to non-permissive $37^{\circ} \mathrm{C}$ and stained with Laurdan. For fluorescence intensity correlations, see Figure S4F. (D) Growth behavior of $f a b A(\mathrm{Ts})$ expressing $\mathrm{F}_{\mathrm{O}} \mathrm{F}_{1} a$-mNG after shift from permissive $30^{\circ} \mathrm{C}$ to non-permissive $37^{\circ} \mathrm{C}$ and upon recovery by supplementation with oleate (cis- $\Delta 9-\mathrm{C} 18: 1$ ). The corresponding reversible segregation of $\mathrm{F}_{\mathrm{O}} \mathrm{F}_{1} a$-mNG is shown above the growth curve. For corresponding controls, see Figure S5C. (A-D) Representative of biological triplicates. (E) Fatty acid composition of $f a b A(\mathrm{Ts})$ cells of panel D upon growth at $30^{\circ} \mathrm{C}$, upon depletion of UFA by incubation at $37^{\circ} \mathrm{C}$ for $2 \mathrm{~h}$, and upon recovery by oleate supplementation for $2 \mathrm{~h}$. For detailed analyses, see Figures S5D-S5F. Means \pm SD of biological triplicates. Scale bar: (A, B, D) $2 \mu \mathrm{m}$; (C) $3 \mu \mathrm{m}$. Strains used: (A, D, E) E. coli MG4; (B) MG4/pBH501; (C) E. coli LF6.red.

Depletion of UFAs had no substantial influence on the DCCD-sensitive ATPase activity of $\mathrm{F}_{\mathrm{O}} \mathrm{F}_{1}$ (Figure S5B), thus arguing that high viscosity of the surrounding lipids does not significantly hinder 
$\mathrm{F}_{\mathrm{O}} \mathrm{F}_{1}$ in its rotation-based catalytic cycle (Junge and Nelson, 2015). In a wider context, this indicates that the remaining fluid phase, to which $\mathrm{F}_{\mathrm{O}} \mathrm{F}_{1}$ partitions upon UFA depletion, can retain robust bioactive properties. Motivated by this surprising observation, we analyzed whether the lipid phase separation behavior associated with growth arrest is lethal, or if it is possible for the cells to recover. Indeed, when severely UFA-depleted $f a b A(\mathrm{Ts})$ cells exhibiting both growth arrest and lipid phase separation were exogenously supplied with oleate, a cis- $\Delta 9-\mathrm{C} 18: 1$ UFA, both growth recovery and restoration of the dispersed distribution of $\mathrm{F}_{\mathrm{O}} \mathrm{F}_{1}$ was observed (Figures 6D and S5C). Corresponding fatty acid analyses revealed an increase in UFA/SFA ratio (Figures 6E and S5D) and MALDI-TOF/TOF mass spectrometry verified the incorporation of oleate into phospholipids (Figures S5E and S5F). Comparable experiments performed with fluorescently labeled glucose permease (PtsG) (Figure S6) confirmed that the observed protein segregation into the fluid phase of phase-separated membranes and its recovery is not unique for ATP synthase.

In summary, our results demonstrate that lipid phase separation occurring under conditions of low membrane fluidity has a profound effect on membrane protein distribution, triggering segregation of integral membrane proteins into the remaining liquid-disordered phase areas.

\section{Restricted diffusion of membrane proteins in UFA-depleted $E$. coli membranes}

One of the membrane processes critical for biological function is lateral diffusion. To analyze the consequences of UFA depletion on protein diffusion, we followed $\mathrm{F}_{\mathrm{O}} \mathrm{F}_{1}$ a-mNG by in vivo single molecule tracking. Consistent with the lack of a specific localization pattern, $\mathrm{F}_{\mathrm{O}} \mathrm{F}_{1} a$-mNG complexes exhibited free diffusion within the plasma membrane plane of E. coli WT cells (Figure 7A and Movie S3). The observed lateral mobilities and jump sizes were largely independent of the growth temperature (Figures 7B and S7A), as can be expected for cells with active homeoviscous adaptation mechanisms in place. At the permissive temperature of $30^{\circ} \mathrm{C}, \mathrm{F}_{\mathrm{O}} \mathrm{F}_{1} a$-mNG expressed in $f a b A(\mathrm{Ts})$ cells also showed unrestricted lateral mobility comparable to WT cells. Under conditions of UFA depletion associated with lipid phase separation $\left(33-40^{\circ} \mathrm{C}\right)$, however, a gradual, temperature-dependent reduction of lateral displacement and median jump sizes was observed (Figures 7A, 7B, S7A, and Movie S4). This is consistent with a local confinement of $\mathrm{F}_{\mathrm{O}} \mathrm{F}_{1}$ caused by lipid phase separation (compare Figure 6A-6C). Calculation of apparent lateral diffusion coefficients $\left(D_{\text {app }}\right)$ revealed that the lateral mobility was reduced up to 9-fold (Figure 7C).

In comparison, single molecule tracking of mNG-labeled WALP23, expressed in $f a b A(\mathrm{Ts})$ cells at $30^{\circ} \mathrm{C}$ also exhibited rapid, unconfined diffusion. As expected based on its smaller number of transmembrane helices (Lucena et al., 2018; Ramadurai et al., 2009), the median jump sizes (Figures S7B and S7C), as well as $D_{\text {app }}$ (Figure S7D) of WALP23 were higher than those observed for $F_{0} F_{1}$ ATP synthase (Figure 7C). Upon lipid phase separation caused by UFA depletion, WALP23 exhibited confined mobility comparable to that observed for $\mathrm{F}_{\mathrm{O}} \mathrm{F}_{1}$ ATP synthase, again supporting the notion that both proteins co-segregate into the remaining fluid phase. 
In summary, depletion of UFA in E. coli indeed results in a strong reduction of membrane fluidity that severely restricts lateral diffusion of membrane proteins as shown by single molecule tracking. As a complementary, dye-independent method, the tracking experiments also confirm the lipid phase separation phenomenon, resulting in integral membrane proteins segregated and confined into the remaining fluid membrane areas.
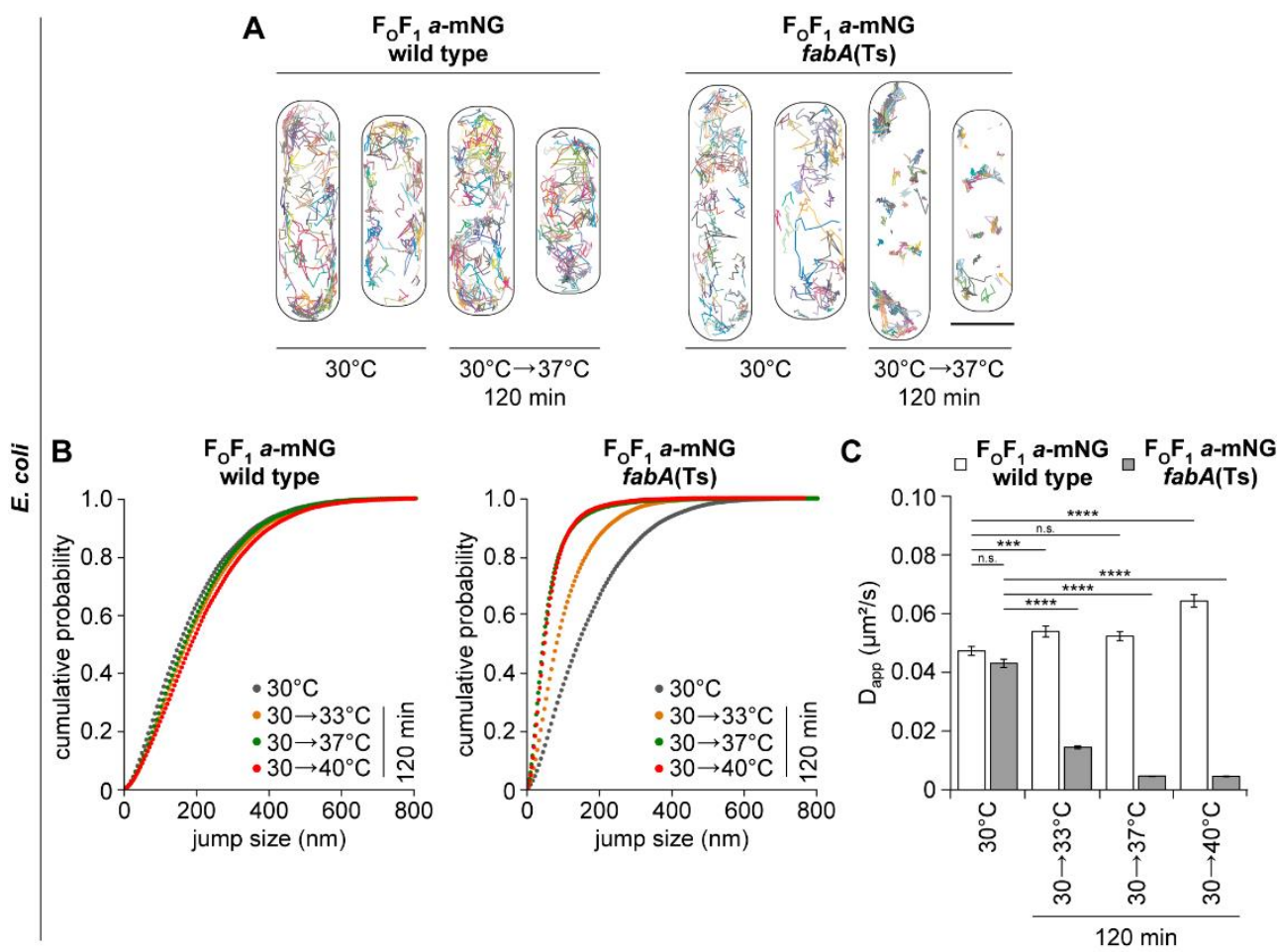

Figure 7. Restricted diffusion of membrane proteins in UFA-depleted $E$. coli membranes. (A) Representative trajectory maps of individual $\mathrm{F}_{\mathrm{O}} \mathrm{F}_{1} a$-mNG molecules in E. coli WT and $f a b A(\mathrm{Ts})$ cells grown at $30^{\circ} \mathrm{C}$ and upon shift to non-permissive $37^{\circ} \mathrm{C}$ for $2 \mathrm{~h}$. See Movies S3 (WT) and S4 (fabA(Ts)) for accumulating trajectory maps of $\mathrm{F}_{\mathrm{O}} \mathrm{F}_{1} a$-mNG molecules. Scale bar, $1 \mu \mathrm{m}$. (B) Cumulative probability plots of $\mathrm{F}_{\mathrm{O}} \mathrm{F}_{1} a$-mNG jump sizes in $E$. coli $\mathrm{WT}$ and $f a b A(\mathrm{Ts})$ cells. $\mathrm{n}=2345-4468$ trajectories with $\geq 5$ consecutive frames for each growth condition and strain were pooled from 3-5 biological replicates and used for analysis. (C) Apparent lateral diffusion coefficients $\left(\mathrm{D}_{\text {app }}\right)$ of $\mathrm{F}_{\mathrm{O}} \mathrm{F}_{1} a-\mathrm{mNG}$ analyzed in panel $\mathrm{B}$. Median \pm SD from biological triplicates together with $\mathrm{P}$ values of a two-sided Wilcoxon rank sum test. Significance was assumed with $* * * * \mathrm{p}<0.0001, * * * \mathrm{p}<0.001, * *<0.01, * \mathrm{p}$ $<0.05$, n.s., not significant. Strains used: (A-C) E. coli MG1, MG4.

\section{Discussion}

Consistent with early studies (Boudreaux et al., 1981; Cronan and Gelmann, 1973; Kaneda, 1977; Willecke and Pardee, 1971), the ability to maintain membrane fluidity through synthesis of fluiditypromoting lipid species is essential for both E. coli and B. subtilis. What is surprising, however, is the magnitude of changes in composition and fluidity the cells can tolerate. While B. subtilis cells finely balance the ratio of iso- and anteiso-BCFA in response to changes in temperature (Klein et al., 1999; Suutari and Laakso, 1992), even the massive changes in the iso/anteiso-ratio obtained through precursor 
supplementation had no significant effect on growth behavior. Similarly, changes in fatty acid composition and membrane fluidity needed to impair growth of $E$. coli are much more drastic than those observed as part of the normal homeoviscous adaptation upon temperature shifts (Mansilla et al., 2004; Marr and Ingraham, 1962; Sinensky, 1974). Consequently, while both E. coli and B. subtilis adapt their membrane composition and fluidity even upon subtle changes in temperature, the failure to do so is not associated with immediate growth-inhibitory consequences. Thus, at least for these organisms, the biological reason for the homeoviscous adaptation process is not directly evident.

A more drastic reduction of membrane fluidity, however, does have severe, growth-inhibitory consequences. Low membrane fluidity associated with lipid phase separation is accompanied by a substantial increase in membrane permeability in vitro (Cordeiro, 2018; Heimburg, 2010; Papahadjopoulos et al., 1973). Our results suggest that, at least in the context of the in vivo plasma membranes of $B$. subtilis and E. coli, this effect does not play a significant role and even the very low fluidity membranes incapable for supporting growth, nevertheless retain robust diffusion barrier function. Rather than indicating ion leakage, the observed gradual and partial membrane depolarization is fully consistent with previous reports demonstrating that the membrane fluidity influences the electron transport chain (ETC) both in E. coli and mitochondria (Budin et al., 2018; Torres et al., 2018). While the enzyme complexes of ETC maintain their function (as we also observed for $\mathrm{F}_{\mathrm{O}} \mathrm{F}_{1}$ ) the diffusivity of ubiquinone is reduced in membranes of low fluidity and thus controls the electron transfer rate in ETC (Budin et al., 2018). Therefore, maintaining robust ETC activity may well be one of the biological reasons why a fine, homeostatic balance of membrane fluidity is important.

In addition to changes in membrane potential, we also observed severe effects on the machineries responsible for cell morphogenesis. The reduction of membrane fluidity in $B$. subtilis is associated with rapid delocalization of MreB indicating disturbance of lateral cell wall synthesis. In $E$. coli, in contrast, both the cell division machinery and the nucleoid morphology were disturbed. However, both cell division and cell wall synthesis machineries are also influenced by membrane depolarization (Strahl and Hamoen, 2010; Strahl et al., 2014). It, thus, remains to be determined whether the observed changes are a direct consequence of low membrane fluidity, or secondarily caused by the gradual membrane depolarization. It is worth highlighting though, that the changes in membrane fluidity required to disturb cell morphogenesis are quite extreme and go well beyond those observed upon normal changes in growth temperature. Consequently, rather than as a sign for sensitivity, these findings provide an indication for the relative robustness of bacterial morphogenetic systems towards normally encountered changes in membrane fluidity.

The most striking phenomenon caused by severe reduction of membrane fluidity is the lipid demixing as well as the changed membrane protein localization pattern. Molecular dynamic simulations with membrane models composed of lipids with SFAs and BCFAs revealed increased ordering of the lipid bilayer when the SFA content was systematically increased. In the presence of approximately $20 \%$ SFAs (compared to 5-7\% in WT), a sharp transition representing phase separation between liquid and 
gel phase was observed (Mostofian et al., 2019). These findings are fully consistent with the lipid demixing we observe upon depletion of BCFAs at cost of SFAs accumulation in B. subtilis, albeit with a slightly higher SFA content needed. In E. coli, we observe in vivo lipid de-mixing upon accumulation of SFA to a content of $80 \%$ (compared to about $50 \%$ in WT (Zhu et al., 2009)), which again is well consistent with previous in vitro studies regarding lipid phase separation of SFA/UFA mixtures (Letellier et al., 1977; Morein et al., 1996; Suárez-Germà et al., 2011). For these reasons, we argue that the observed de-mixing represents lipid phase separation between liquid-disordered and gel state membranes occurring in living cells. While the phase separation phenomenon unarguably affects the plasma membranes both in Gram-positive B. subtilis and Gram-negative E. coli, we suggest that the process is limited to the plasma membrane and does not encompass the Gram-negative outer membrane. This is based on the irregular FM 5-95 membrane staining only observed in B. subtilis, whereas staining of E. coli, in which the dye stains the outer membrane (Pilizota and Shaevitz, 2012), remains smooth even under conditions of severe UFA depletion.

The specificity of dyes to label different lipid phases is still a matter of debate. Small hydrophobic dyes may themselves alter the composition and ordering of coexisting phases, even when used in trace amounts (Veatch, 2007). However, we are convinced that (i) by using the combination of two chemically distinct fluorescent membrane dyes Laurdan and FM 5-95 exhibiting opposing phase preferences, (ii) combining dye-based approaches with localization of WALP23 peptide previously shown to exhibit liquid-disordered phase preference both in vivo, in vitro, and in silico (Ridder et al., 2004; Schäfer et al., 2011; Scheinpflug et al., 2017b), and (iii) by following the reversible phase separation through its consequences on lateral membrane protein diffusion, we have exhausted the possibility that the observed phase separation is an artefact caused by the labeling techniques used.

Importantly, by demonstrating lipid liquid-gel phase separation and the associated membrane protein segregation occurring in protein-crowded, native membranes of living cells, our results are fully consistent with comparable phenomena observed in simplified in vitro and in silico model systems (Domański et al., 2012; Picas et al., 2010; Suárez-Germà et al., 2011), thus providing strong, complementary in vivo support for the general validity of the respective membrane models.

It is perhaps not surprising that the observed lipid phase separation coincides with growth arrest. Transmembrane segments of integral membrane proteins are embedded within the hydrophobic interior of lipid bilayers. Consequently, lipid bilayer thickness, which acutely changes with membrane fluidity and phase, is both important for membrane protein activity, and drives partitioning of proteins between different phases (Lee, 2004; Lenaz, 1987; Lorent et al., 2017; Nickels et al., 2019). Peripheral membrane proteins, which establish membrane association through bilayer-intercalating domains such as amphipathic helices, in turn rely on sufficiently low packing density/high fluidity for efficient membrane association (Bigay and Antonny, 2012; Drin and Antonny, 2010; Strahl and Errington, 2017). At last, the severe restriction of lateral diffusion caused by phase separation is likely interfering with localization and activity of many membrane-associated cellular processes relying on diffusion and capture 
mechanism (Rudner et al., 2002). As suggested earlier (Burns et al., 2017; Drobnis et al., 1993; Ghetler et al., 2005), we argue that it is indeed the lipid phase separation process and the formation of gel phase areas that determines the lower end of membrane fluidity capable of supporting viable cell functions.

\section{Materials and Methods}

\section{Construction of $E$. coli strains}

E. coli strains MG1 or EB8.1 carrying a C-terminal mNeonGreen or mCherry fusion to the membraneintegral $\mathrm{F}_{\mathrm{O}}-a$ subunit, respectively, were generated using the phage $\lambda$ Red recombinase to replace a chromosomal sequence (Datsenko and Wanner, 2000). Briefly, the kanamycin resistance cassette of strain EB4 ( $\triangle a t p B E:: F R T-k a n-F R T)$ was exchanged by the HindIII/AseI fragment of plasmids pBH189 (MG1) or pEB21.2 (EB8.1), followed by growth on M9 minimal medium (see below) with succinate $(0.4 \%(w / v))$ as sole carbon source for selection. As expected, both strains show a $\mathrm{Succ}^{+} \mathrm{Kan}^{\mathrm{S}}$ phenotype. In detail, EB4 cells transformed with temperature-sensitive plasmid pKD46 encoding $\lambda$ Red recombinase genes under control of the ParaBAD promoter were grown at $30^{\circ} \mathrm{C}$ to mid-logarithmic phase in lysogenic broth (LB) composed of yeast extract $(0.5 \% \mathrm{w} / \mathrm{v})$, tryptone $(1 \% \mathrm{w} / \mathrm{v}), \mathrm{NaCl}(1 \% \mathrm{w} / \mathrm{v})$ (Sambrook et al., 1990) and supplemented with arabinose $(0.2 \% \mathrm{w} / \mathrm{v})$ for induction. Competent cells were prepared by wash with ice-cold water for removal of salts and medium components, electroporated in the presence of the corresponding DNA fragment for $1 \mathrm{~ms}$ at $1.25 \mathrm{kV}$, grown for $1 \mathrm{~h}$ in $\mathrm{LB}$ at $37^{\circ} \mathrm{C}$ for phenotypic expression, and plated on selective solid medium.

Several E. coli strains were obtained by P1 transduction (Thomason et al., 2007). In detail, P1 liquid lysate was generated by growing the donor strain to optical density at $600 \mathrm{~nm}\left(\mathrm{OD}_{600}\right)$ of $0.1 \mathrm{in}$ LB medium ( $3 \mathrm{ml}$ ), adding $\mathrm{CaCl}_{2}(330 \mu 150 \mathrm{mM})$ and P1 lysate (20 $\mu 1$ of $\sim 10^{-9}$ phages $\left./ \mathrm{ml}\right)$, and further growing with good aeration until lysis occurred. 5 drops of chloroform were added to lyse remaining cells, centrifuged twice to pellet debris, and the supernatant was stored with 2 drops of chloroform in the dark at $4^{\circ} \mathrm{C}$. For transduction, an overnight culture of the recipient strain $(200 \mu \mathrm{l})$ was mixed with $\mathrm{CaCl}_{2}(28 \mu \mathrm{l} 50 \mathrm{mM})$ and $\mathrm{P} 1$ lysate $(50 \mu \mathrm{l})$ of the donor strain and incubated for $20 \mathrm{~min}$ at $37^{\circ} \mathrm{C}$. After addition of $\mathrm{Na}_{3}$-citrate $(100 \mu \mathrm{l} 1 \mathrm{M})$ and LB medium $(0.7 \mathrm{ml})$ and further incubation for $40 \mathrm{~min}$, cells were plated on selective solid medium containing $\mathrm{Na}_{3}$-citrate $(20 \mathrm{mM})$.

Strain LF4 was obtained using EB4 as donor, UC1098 (kindly provided by J.E. Cronan, Jr. (Illinois)) as recipient and LB medium with kanamycin $(50 \mu \mathrm{g} / \mathrm{ml})$ for selection, leading to a $\mathrm{Succ}^{-} \mathrm{Kan}^{\mathrm{R}}$ phenotype. Subsequently, MG4 and LF6.red were generated by P1 transduction using MG1 and EB8.1 as respective donor strains, LF4 as recipient, and minimal medium with succinate for selection as described above. For generation of strains BHH100 and BHH101 by P1 transduction, MG1655.mreBmsfGFP and KC555, were used as respective donor strains, UC1098 as recipient, and LB with kanamycin $(50 \mu \mathrm{g} / \mathrm{ml})$ or chloramphenicol $(12.5 \mu \mathrm{g} / \mathrm{ml})$ for selection. In all strains, the fusion genes of interest were verified by colony PCR and DNA sequencing. All strains used are listed in Table S1. 


\section{Construction of $E$. coli plasmids}

For construction of plasmids pBH189 and pEB21.2, a BamHI site (encoding a Gly-Ser linker) and genes encoding mNeonGreen (pBH189) and mCherry (pEB21.2), respectively, were inserted into the atp operon of plasmid pBWU13 prior to the stop codon of atpB using a two-step PCR overlap extension method. First, three individual PCR products were generated using (i) oligonucleotides $1 / 2$ with pSD166 as a template, (ii) oligonucleotides 3/4 with pNCS-mNeonGreen as a template for pBH189 or with pQW58 as a template for pEB21.2, and (iii) oligonucleotides 5/6 with pSTK3 as template. The three PCR products and oligonucleotides $1 / 6$ were used for the second amplification step. HindIII/AseIdigested PCR products were cloned into correspondingly digested pBH4.

For construction of plasmids pBH500 and pBH501, a linker encoding SGSGSG, and the open reading frames (ORF) encoding mNeonGreen and mScarlet-I, respectively, were fused with WALP23ORF by two-step PCR. Briefly, for plasmid pBH500, two different PCR products were obtained using oligonucleotides 7/8 with pL030 as template and oligonucleotides 10/11 with pNCS-mNeonGreen as template. For the second PCR step, oligonucleotides 7/11 were used. For plasmid pBH501, two PCR products were obtained using oligonucleotides 7/9 with pL030 as template and oligonucleotides 12/13 with synthesized mScarlet-I-encoding DNA as template. For the second PCR step, oligonucleotides 7/13 were used. In both cases, AvrII/SpeI-digested PCR products were cloned into correspondingly digested pL030. All constructs were verified by DNA sequencing and listed in Table S2. Oligonucleotides used are listed in Table S3.

\section{Construction of $B$. subtilis strains}

For construction of a B. subtilis strain (Table S1) expressing WALP23 fused to monomeric superfolder GFP (msfGFP), the plasmid pBH500 was linearized with oligonucleotides 14 and 15, msfGFP amplified using oligonucleotides 16 and 17 (Table S3), and the fragments fused using NEBuilder® HiFi DNA Assembly Cloning Kit (New England Biolabs). The resulting plasmid was transformed into B. subtilis 168, thus resulting in strain JG054. All other B. subtilis strains were constructed by transforming the respective recipient strains with chromosomal DNA from the donor strains or corresponding plasmid DNA. The transformations were carried out as described in Hamoen et al. (Hamoen et al., 2002).

\section{E. coli strains and growth conditions}

E. coli strains were grown in M9 minimal medium (Sambrook et al., 1990) composed of $\mathrm{Na}_{2} \mathrm{HPO}_{4} \cdot 2 \mathrm{H}_{2} \mathrm{O}$ $(0.85 \% \mathrm{w} / \mathrm{v}), \mathrm{KH}_{2} \mathrm{PO}_{4}(0.3 \% \mathrm{w} / \mathrm{v}), \mathrm{NaCl}(0.3 \% \mathrm{w} / \mathrm{v}), \mathrm{NH}_{4} \mathrm{Cl}(0.05 \% \mathrm{w} / \mathrm{v}), \mathrm{MgSO}_{4} \cdot 7 \mathrm{H}_{2} \mathrm{O}(0.25 \% \mathrm{w} / \mathrm{v})$, $\mathrm{CaCl}_{2} \cdot 2 \mathrm{H}_{2} \mathrm{O}(0.015 \% \mathrm{w} / \mathrm{v})$ and supplemented with thiamine $(0.01 \% \mathrm{w} / \mathrm{v})$, casamino acids $(0.1 \% \mathrm{w} / \mathrm{v})$, and glucose $(0.4 \% \mathrm{w} / \mathrm{v})$ at $30^{\circ} \mathrm{C}$, unless stated otherwise. In case of $p t s G$ - $g f p$ expression, glycerol $(0.4 \%$ w/v) was used instead of glucose as carbon source. For induction of the temperature-sensitive phenotype fabA(Ts), pre-cultures of E. coli strain UC1098 and its derivatives were diluted from an overnight culture to an $\mathrm{OD}_{600}$ of 0.025 and grown to $\mathrm{OD}_{600}$ of 0.5 at $30^{\circ} \mathrm{C}$, and again diluted to $\mathrm{OD}_{600}$ of 0.05 in 
pre-warmed, fresh medium. At $\mathrm{OD}_{600}$ of 0.1-0.2, cells were transferred for $2 \mathrm{~h}$ to growth temperatures of $33^{\circ} \mathrm{C}, 37^{\circ} \mathrm{C}$ or $40^{\circ} \mathrm{C}$ (in a pre-warmed water bath) as indicated. The corresponding wild type strains were handled accordingly. For recovery from UFA depletion and corresponding phase separation, UC1098 derivatives were subsequently supplemented with potassium oleate $(100 \mu \mathrm{g} / \mathrm{ml})$ dissolved in $\mathrm{Brij}^{\circledR} 58(0.1 \% \mathrm{w} / \mathrm{v}) . \mathrm{F}_{\mathrm{O}} \mathrm{F}_{1}$ ATP synthase fluorescently labeled with $\mathrm{mNG}$ or mCherry at the C terminus of $\mathrm{F}_{\mathrm{O}}-a\left(\mathrm{~F}_{\mathrm{O}} \mathrm{F}_{1} a\right.$-mNG or $\mathrm{F}_{\mathrm{O}} \mathrm{F}_{1} a$-mCherry), as well as msfGFP sandwich fusions of FtsZ and MreB were expressed from their own locus under control of their native promoter. Fluorescently labelled WALP23 (AWW(LA) $)_{8}$ LWWA) peptides (WALP23-mScarlet-I or WALP23-mNG) were expressed plasmidencoded under control of the B. subtilis Pxyl promoter that resulted in strong, constitutive expression in E. coli. Plasmid-encoded expression of PtsG-GFP (pBLP2) was under control of the ParaBAD promoter and induced with arabinose $(0.01 \% \mathrm{w} / \mathrm{v})$.

\section{B. subtilis strains and growth conditions}

For strain construction, B. subtilis was grown either in LB, Nutrient Broth, or Nutrient Agar (Oxoid). If necessary, these media were supplemented with either isobutyric acid (IB) $(100 \mu \mathrm{M})$ or 2-methylbutyric acid (MB) (100 $\mu$ M; Sigma Aldrich). All other experiments were carried out with fortified Spizizen minimal medium (Anagnostopoulos and Spizizen, 1961) composed of $\left(\mathrm{NH}_{4}\right)_{2} \mathrm{SO}_{4}(0.2 \% \mathrm{w} / \mathrm{v}), \mathrm{K}_{2} \mathrm{HPO}_{4}$ $\left(1.4 \%\right.$ w/v), $\mathrm{KH}_{2} \mathrm{PO}_{4}\left(0.6 \%\right.$ w/v) $\mathrm{Na}_{3}$-citrate $2 \mathrm{H}_{2} \mathrm{O}\left(0.1 \%\right.$ w/v), $\mathrm{MgSO}_{4}(0.09 \%$ w/v), ferric ammonium citrate $(1.1 \mu \mathrm{g} / \mathrm{ml})$ and supplemented with glucose $(0.96 \% \mathrm{w} / \mathrm{v})$, L-tryptophan $(20 \mu \mathrm{g} / \mathrm{ml})$, and casamino acids $(0.02 \% \mathrm{w} / \mathrm{v})$. In our hands, the precursor isovaleric acid, which is the primer for the synthesis of iso-C15:0 and iso-C17:0, neither supported growth nor resulted in synthesis of the expected isobranched chain fatty acids, thus implying that this precursor cannot be supplied exogenously in the B. subtilis 168 strain background. All cultures were inoculated by 1:100 dilution of an LB overnight culture supplemented with the corresponding precursor. Depletion of branched chain fatty acids was carried out for cells initially grown in the presence of IB $(100 \mu \mathrm{M})$, followed by washing, pelleting, and resuspension in pre-warmed, precursor-free medium (PF). Unless stated otherwise, all experiments were carried out at $37^{\circ} \mathrm{C}$. Fluorescently labeled WALP23 peptides (WALP23-mCherry or WALP23msfGFP), msfGFP-MreB as well as GFP-FtsZ were expressed ectopically (amyE locus) under control of the Pxyl promoter and induced by xylose (1\% w/v; $0.3 \% \mathrm{w} / \mathrm{v}$ in case of GFP-FtsZ).

\section{Determination of fatty acid composition}

The fatty acid composition of E. coli and B. subtilis was determined from 50-100 mg (wet weight) of bacterial cells grown as described above. Fatty acids were extracted as methyl esters after saponification and methylation as described by Sasser (1990). For saponification, cell pellets were mixed with 15\% $(\mathrm{w} / \mathrm{v}) \mathrm{NaOH}$ in $50 \%(\mathrm{v} / \mathrm{v})$ methanol $(1 \mathrm{ml})$, incubated at $100^{\circ} \mathrm{C}$ for $5 \mathrm{~min}$, vortexed, and further incubated for $25 \mathrm{~min}$. After cooling, acid methylation with $6 \mathrm{~N} \mathrm{HCl}$ in $50 \%(\mathrm{v} / \mathrm{v})$ methanol (2 ml) was performed for $10 \mathrm{~min}$ at $80^{\circ} \mathrm{C}$ followed by immediate cooling on ice. Methylated fatty acids were extracted by 
addition of hexane/methyl tert-butylether in a 1:1 ratio $(1.25 \mathrm{ml})$, followed by end-over-end incubation for $10 \mathrm{~min}$. After phase separation by centrifugation, the lower phase was discarded. The organic phase was washed with $1.2 \%(\mathrm{w} / \mathrm{v}) \mathrm{NaOH}(3 \mathrm{ml})$ by $5 \mathrm{~min}$ end-over-end incubation and centrifugation. The upper phase of the phase-separated sample was used for further analysis.

The fatty acid methyl esters (FAME) were separated and identified by gas chromatographymass spectrometry (GC-MS) with a gas chromatograph (model 7890A; Agilent Technologies) equipped with a 5\% phenylmethyl silicone capillary column and a mass spectrometer (model 5975C; Agilent Technologies). Helium was used as carrier gas, injection volume was $1 \mu 1$, injector temperature was $250^{\circ} \mathrm{C}$, the column temperature was increased from 120 to $240^{\circ} \mathrm{C}$ at a rate of $5^{\circ} \mathrm{C} / \mathrm{min}$, and the GC-MS line transfer temperature was $280^{\circ} \mathrm{C}$. FAME were separated by their retention times and identified by their equivalent chain lengths (ECL) and their mass spectra. ECL values were calculated from linear interpolation of unknown peaks' retention time between two saturated straight chain FAME of a standard.

\section{Glycerophospholipid analysis by MALDI-TOF mass spectrometry}

Extraction of lipids from bacterial cells was performed according to Gidden et al. (Gidden et al., 2009) as follows. $10^{10}$ cells (assuming that $1 \mathrm{ml}$ of cell culture with $\mathrm{OD}_{600}$ of 1.0 contains $10^{9}$ cells (Neidhardt et al., 1990) were harvested, washed twice with cooled water, and extracted with $450 \mu \mathrm{l}$ of dichloromethane:ethanol:water 1:1:1 (v:v:v) overnight at $4^{\circ} \mathrm{C} .1 \mu \mathrm{l}$ of the lipid-containing lower organic phase was spotted on a MALDI target plate (Prespotted AnchorChip 96 Set for Proteomics II; Bruker Daltonics/Eppendorf) pre-spotted with $1 \mu \mathrm{l}$ of 9 -aminoacridine $(10 \mathrm{mg} / \mathrm{ml}$ dissolved in acetone:water 9:1 (v/v)) and air-dried. Mass spectra were obtained on an ultrafleXtreme MALDI-TOF/TOF mass spectrometer equipped with a smartbeam ${ }^{\mathrm{TM}}$ solid state laser (Bruker Daltonics) operating in the negative ion mode. The laser was fired with a frequency of $500 \mathrm{~Hz}$ with $4 \times 250$ laser shots per spot. MS/MS spectra were obtained using the 'LIFT' technique implemented in the mass spectrometer (Suckau et al., 2003) with an increased laser power. Samples from three independent repeats were measured per condition as technical triplicates, compared with corresponding standard lipids $\operatorname{PE}(16: 0)(18: 1)$ and PG(16:0)(18:1) (Avanti polar lipids) in MS as well as MS/MS spectra, and analyzed with FlexAnalysis 3.4 (Bruker Daltonics).

\section{DPH anisotropy measurements}

Steady state DPH fluorescent anisotropy measurements were carried out with 1,6-Diphenyl-1,3,5-hexatriene (DPH; Sigma Aldrich) -labeled cells using a BMG Clariostar multimode plate reader (BMG Latec). For B. subtilis, cells taken from cultures at the time points of interests were diluted to an $\mathrm{OD}_{600}$ of 0.25 in a pre-warmed medium, followed by addition of DPH dissolved in dimethyl formamide (DMF) to a final concentration of $10 \mu \mathrm{M}$ DPH and $1 \%(\mathrm{v} / \mathrm{v})$ DMF. Samples were shaken in dark at $37^{\circ} \mathrm{C}$ for 5 $\mathrm{min}$, followed by a wash and resuspension in dye-free medium to an $\mathrm{OD}_{600}$ of 0.5 , and transfer to pre- 
warmed, black, polystyrene 96-well microtiter plates (Labsystems) for measurement. Following 1 min incubation under shaking in the pre-warmed plate reader to homogenize the sample, the anisotropy was measured at $37^{\circ} \mathrm{C}$ using excitation wavelength of $360-10 \mathrm{~nm}$, emission wavelength of $450-10 \mathrm{~nm}$, and a dichroic mirror set at $410 \mathrm{~nm}$. The fluorescence anisotropy (A) was calculated with MARS Data Analysis software (BMG Labtec) using the equation ( $\left.\mathrm{I}_{\text {parallel }}-\mathrm{I}_{\text {perpendicular }}\right) /\left(\mathrm{I}_{\text {parallel }}+2 \mathrm{xI}_{\text {perpendicular }}\right)$. The corresponding measurements for E. coli were carried out using the same protocol with following modifications. The staining was carried out with cells grown in the presence of non-growth inhibitory concentrations $(30 \mu \mathrm{g} / \mathrm{ml})$ of the outer membrane-permeabilizing agent Polymyxin B nonapeptide (Lam et al., 1986), which is required for good staining of E. coli with DPH. The measurements at $30^{\circ} \mathrm{C}$ and $37^{\circ} \mathrm{C}$ without temperature shifts were carried out with all media, plastic ware, and the plate reader prewarmed to the corresponding temperatures. The rapid temperature shift from $30^{\circ} \mathrm{C}$ to $37^{\circ} \mathrm{C}$ was carried out with cells grown, stained, and washed at $30^{\circ} \mathrm{C}$, followed by final resuspension in buffer pre-warmed to $37^{\circ} \mathrm{C}$, and measurement with microtiter plate and the plate reader pre-warmed to $37^{\circ} \mathrm{C}$.

\section{Fluorescence microscopy}

Regular wide field fluorescence microscopy was carried out with cells immobilized on Teflon-coated multi-spot microscope slides (Hendley-Essex) with $1.2 \%(\mathrm{w} / \mathrm{v})$ agarose $/ \mathrm{H}_{2} \mathrm{O}$ (Te Winkel et al., 2016). In brief, after the agarose solidified within $10 \mathrm{~min}$ at room temperature, $0.5 \mu \mathrm{l}$ of a cell culture were applied to the exposed agarose surface, air-dried until the liquid-drop was soaked in, covered with a coverslip, and immediately used for microscopy. For staining with various fluorescent dyes, cells were incubated upon shaking at the growth temperature for 5 min with following concentrations: FM 5-95 (2 $\mu \mathrm{g} / \mathrm{ml}), \operatorname{DiSC}_{3}(5)(2 \mu \mathrm{M})$, Sytox Green (50 ng/ml), DAPI (200 ng/ml). Membrane depolarization of B. subtilis was achieved by $5 \mathrm{~min}$ incubation with small cation specific channel-forming antimicrobial peptide Gramicidin ABC (10 $\mu \mathrm{M}$; gABC) (Kelkar and Chattopadhyay, 2007), and membrane permeabilization by $5 \mathrm{~min}$ incubation with pore-forming lantibiotic Nisin $(10 \mu \mathrm{M})$ (Wiedemann et al., 2004). In case of E. coli, membrane depolarization and permeabilization was achieved by $15 \mathrm{~min}$ incubation in the presence of pore-forming antibiotic Polymyxin B (10 $\mu \mathrm{g} / \mathrm{ml})$ (Daugelavicius et al., 2000). Laurdan microscopy was carried out with cells stained with $100 \mu \mathrm{M}$ Laurdan (dissolved in $1 \%$ (v/v) DMF) as described in detail elsewhere (Scheinpflug et al., 2017a; Wenzel et al., 2018). As in case of DPH, the staining of E. coli was carried out with Polymyxin B nonapeptide outer membranepermeabilized cells. The time lapse microscopy of B. subtilis was carried out with the fortified Spizizen minimal medium with concentration of the carbon sources (glucose, tryptophan, and casamino acids) diluted to one tenth, and supplemented with $1.4 \%(\mathrm{w} / \mathrm{v})$ low-melting point agarose. The slide preparation was carried out as described (de Jong et al., 2011).

The fluorescence microscopy of B. subtilis and E. coli cells stained with FM 5-95, $\mathrm{DiSC}_{3}(5)$, Sytox Green, Laurdan or expressing fluorescent protein fusions was performed at $37^{\circ} \mathrm{C}$ with Nikon Eclipse Ti equipped with either Sutter Instruments Lambda LX Xenon-arc light source (Figure 3) or 
CoolLed pE-300white LED light source (Figures 4, 5B-5E, 6C, S3A, and S4C), Photometrics Prime sCMOS camera, and either Nikon Plan Fluor 100x/1.30 NA Oil Ph3 (Movie S1 and Figure 5A), Nikon CFI Plan Apo VC 100x/1.40 NA (Figures 5B and 5C), or Nikon Plan Apo 100×/1.40 NA Oil Ph3 (Figures 3, 4, 5D, 5E, 6C, S3A, and S4C, ) objectives. The used filter sets were Chroma 49000 (for DAPI and Laurdan $460 \mathrm{~nm}$ ), Chroma 49002 (for GFP and Sytox Green), Chroma 49008 (for mCherry, mScarlet-I, and FM 5-95), Semrock Cy5-4040C (for $\operatorname{DiSC}_{3}(5)$ ), and a custom filter set consisting of Chroma AT350/50x excitation filter, Chroma T400lp beam splitter, and Chroma ET525/50m (for Laurdan $520 \mathrm{~nm}$ ). All images were analyzed using Fiji (Schindelin et al., 2012). Laurdan GP maps were calculated and generated using the ImageJ-macro described by Wenzel et al. (Wenzel et al., 2018). The localization correlation analysis was carried out with the Fiji plugin Coloc 2, using a 3 pixel wide line following the cell periphery as a region of interest.

For E. coli fabA(Ts) time lapse microscopy (Movie S2 and Figure 6A) as well as wide field fluorescence microscopy (Figures 6B, 6D, S3B, and S6), microscope slides were coated with a thin film of $1 \%(\mathrm{w} / \mathrm{v})$ agarose dissolved in M9 minimal media supplemented with glycerol and arabinose (PtsG microscopy) or supplemented with glucose (all other experiments) as described above. Cells ( $3 \mu \mathrm{l})$ were immobilized and imaged with a DeltaVision Elite microscopy system (Applied Precision, GE Healthcare) equipped with an inverted microscope (IX-71, Olympus), a 100x oil immersion objective (UAPON 100x TIRF, Olympus), solid state illumination system (Insight SSI, Applied Precision), a sCMOS camera (pco.edge 4.2, PCO), and acquisition software (softWoRx 5.5, Applied Precision). Fluorescence of mNeonGreen and mScarlet-I was excited using a Polychroic beamsplitter $(405 \mathrm{~nm} / 488$ $\mathrm{nm} / 590 \mathrm{~nm} / 650 \mathrm{~nm})$ as well as either a GFP/FITC bandpass filter (461-489 nm) or mCherry/Alexa594 bandpass filter (562-588 nm). Fluorescence detection was achieved using a GFP/FITC bandpass emission filter (501-559 nm) for mNeonGreen and a mCherry/Alexa594 bandpass emission filter (602$648 \mathrm{~nm}$ ) for mScarlet-I, respectively.

For E. coli time lapse microscopy, z-Stacks of $300 \mathrm{~nm}$ in 5 optical slices were acquired of cells growing on the microscope slide with the microscope tempered to the corresponding temperature and imaged for $2.5 \mathrm{~h}$ with $5 \mathrm{~min}$ intervals using an exposure time per frame of $50 \mathrm{~ms}$. Image processing, including generation of movies, was performed with Fiji.

\section{Single molecule tracking}

Single molecule imaging of $E$. coli cells expressing $\mathrm{F}_{\mathrm{O}} \mathrm{F}_{1}$ ATP synthase with $\mathrm{F}_{\mathrm{O}}-a$ fused to $\mathrm{mNeonGreen}$ was performed using an total internal reflection fluorescence (TIRF) microscopy system equipped with an inverted microscope (IX-83, Olympus), a motorized four-line TIRF condenser (cellTIRF, Olympus), an 150x oil immersion objective (UAPON 150x/1.45 NA TIRF, Olympus), an EMCCD camera (iXON Ultra 897, Andor), and the acquisition software CellSens 2.3 (Olympus). Fluorescence of mNeonGreen was excited by a $488 \mathrm{~nm}$ laser diode (LuxX 488-200, Omicron) using a TIRF pentaband polychroic mirror (zt405/488/561/640/730rpc, Chroma). Fluorescence detection and efficient TIR laser blocking 
was achieved by a pentabandpass emission filter (BrightLine HC 440/521/607/694/809, Semrock) and an additional single bandpass emission filter (BrightLine HC 525/35, Semrock). Single cell fluorescence was pre-bleached for $2.5 \mathrm{~s}$ at $10 \%$ laser intensity (approx. $1.5 \mu \mathrm{W} / \mu \mathrm{m}^{2}$ ) in order to obtain single molecule level. Subsequently, single emitter signals were imaged at 30 frames per second for 1200 frames $(40 \mathrm{~s})$ with 5\% of laser intensity. All experiments were carried out at room temperature for comparability. Tracking of single molecules as well as additional data analysis was carried out with well-established localization and tracking algorithms (Jaqaman et al., 2008; Serge et al., 2008), implemented in a software package called 'SLIMfast' (kindly provided by C.P. Richter) written in Matlab (Appelhans et al., 2018; Richter et al., 2017). Localization precision was typically about 20-25 nm. Between 900 and 1000 frames per image series were used for further step length and diffusion constant analysis. Step length analysis is based on trajectories exhibiting at least five sequential frames (excluding deflation loops and frame gaps). Typically, the population of all trajectories is approximately twice as high as those taken into account (step size of $\geq 5$ ) in Figures 7 and S7.

Analysis of lateral mobility was performed via cumulative probability plots with jump sizes of pooled trajectories from three separately grown cell batches and via boxplots to determine the median of all trajectories present within individual cells. Apparent two-dimensional diffusion coefficients $D_{a p p}$ were estimated by the mean-squared displacement (MSD) $\left\langle(\Delta r(\tau))^{2}\right\rangle=4 D_{a p p} \tau$ considering a linear free diffusion model. Here, $\tau=\Delta t, 2 \Delta t, \ldots, n \Delta t$ is the lag time defined by multiples of time interval $\Delta t$ of the image series. For all trajectories with at least $\geq 5$ five sequential frames, MSD was averaged and the diffusion coefficient was calculated by the slope of a linear fit based on the first four data points of the MSD. For determination of standard error, the statistical resampling method of bootstrapping was used, evaluating data sets with $\mathrm{N}$ data points 1000-times (Bradley, 1981).

\section{Membrane vesicles and DCCD-sensitive ATPase activity}

Inverted membrane vesicles were prepared as previously described (Brandt et al., 2013) using $850 \mathrm{ml}$ of cell cultures grown under conditions stated above. After harvest, cell pellets were resuspended in 25 $\mathrm{ml} 50 \mathrm{mM}$ Tris-HCl, pH 7.5, $10 \mathrm{mM} \mathrm{MgCl}_{2}, 10 \%$ (v/v) glycerol and disrupted in the presence of 10 $\mu \mathrm{g} / \mathrm{ml}$ DNaseI (Sigma) with a constant cell disruptor system (Daventry) at $4^{\circ} \mathrm{C}$ and $1.35 \mathrm{kbar}$. For removal of cell debris, lysates were centrifuged at $35000 \mathrm{xg}$, for $30 \mathrm{~min}$ at $4^{\circ} \mathrm{C}$. After ultracentrifugation of the supernatant at $250000 \mathrm{xg}$ at $4^{\circ} \mathrm{C}$ for $60 \mathrm{~min}$, membranes were resuspended with a marten paint brush in a small aliquot (0.3-0.5 ml) of the same buffer and stored in liquid nitrogen.

ATPase activities of inverted membrane vesicles were determined using an automated continuous assay enabling a direct recording of the substrate turnover (Arnold et al., 1976). After addition of substrate, samples were preincubated for $2 \mathrm{~min}$ at $37^{\circ} \mathrm{C}$, vortexed, connected to a pump, and the released phosphate continuously measured for $7 \mathrm{~min}$ at $37^{\circ} \mathrm{C}$ adding consecutively $(i)$ air bubbles to generate small reaction chambers, (ii) trichloroacetic acid/SDS to stop the reaction, (iii) acid molybdate to form phosphomolybdate, and (iv) ascorbate to reduce phosphomolybdate to molybdenum blue. 
Finally, after removal of air, the increase in absorbance was measured at $578 \mathrm{~nm}$ in a $50 \mu \mathrm{l}$ flow-through cuvette and recorded. Membranes were incubated in $50 \mathrm{mM}$ Tris- $\mathrm{HCl}$, $\mathrm{pH} 8.0,1 \mathrm{mM} \mathrm{MgCl}_{2}$, and $1 \mathrm{mM}$ ATP using a volume of $10 \mathrm{ml}$. For inhibition of ATPase activities with $80 \mu \mathrm{M}$ DCCD (in ethanol), membranes were incubated in $1 \mathrm{ml}$ of $50 \mathrm{mM}$ Tris- $\mathrm{HCl}, \mathrm{pH} 8.0$ for $20 \mathrm{~min}$ at $37^{\circ} \mathrm{C}$ prior to measurement (Deckers-Hebestreit and Altendorf, 1992).

\section{SDS-PAGE and Western Blot}

Protein concentrations were determined with the BCA assay as recommended by the supplier (Pierce). Proteins $(20 \mu \mathrm{g} / \mathrm{lane})$ were separated by SDS-PAGE using $10 \%$ tris-tricine gels $(10 \% \mathrm{~T}, 3 \% \mathrm{C})$ according to Schägger and von Jagow (1987) with PageRuler ${ }^{\mathrm{TM}}$ prestained protein ladder (Fermentas) as standard. For immunoblotting, separated proteins were transferred to nitrocellulose membranes $(0.45$ $\mu \mathrm{m})$ via wet blotting in carbonate buffer $\left(10 \mathrm{mM} \mathrm{NaHCO}_{3}, 3 \mathrm{mM} \mathrm{Na}_{2} \mathrm{CO}_{3}, \mathrm{pH} 8.9\right.$ with $\mathrm{NaOH}, 20 \%$ (v/v) methanol) for $45 \mathrm{~min}$ at $1.8 \mathrm{~A}$ with cooling (Hilbers et al., 2013). Membranes were blocked with $5 \%$ (w/v) skimmed milk powder in TBS buffer (50 mM Tris/HCl pH 7.4, 0.9\% (w/v) NaCl), decorated with monoclonal mouse antibodies specific for $\mathrm{F}_{\mathrm{O}}-a$ (GDH 14-5C6; Jäger et al., 1998) or mNeonGreen (32F6, ChromoTek) and secondary IRDye ${ }^{\mathrm{TM}} 800 \mathrm{DX}$-labeled goat-anti-mouse IgG (H+L) (LI-COR Biosciences), and detected using a two-channel Odyssey infrared imaging System (LI-COR Biosciences).

\section{Quantification and statistical analysis}

Details on statistics used can be found in figure legends. Statistical analysis was performed using a twosided Wilcoxon rank sum test in MATLAB R2013a (MathWorks) or an unpaired two-sided t-test using GraphPad Prism 8 or Microsoft Excel. Error bars represent standard deviation (SD) from three independent biological replicates, unless stated otherwise. The $n$ value of imaging-based experiments represents the number of bacterial cells used for each experimental condition, whereas in case of single molecule tracking, the $\mathrm{n}$ value represents the number of trajectories with $\geq 5$ consecutive frames. Significance was assumed with $* * * * \mathrm{p}<0.0001$, $* * * \mathrm{p}<0.001, * *<0.01, * \mathrm{p}<0.05$, n.s., not significant.

\section{Software used}

The following software was used: Image Studio 5.2 (Western blot detection and analysis), ChemStation (fatty acid analysis), MARS Data Analysis software (DPH anisotropy calculation), SoftWoRx (image acquisition in DeltaVision fluorescence microscopy), Metamorph 7.7 (image acquisition in Nikon Eclipse Ti fluorescence microscopy), CellSens 2.3 (image acquisition for single-molecule tracking), ImageJ (image analysis and quantification), SLIMfast (software for localization-based imaging in Matlab (R2013a, Mathwork), FlexControl 3.4 (MALDI-TOF data acquisition), FlexAnalysis 3.4 (MALDI-TOF data analysis), GraphPad 8 (figure preparation), OriginPro 8 (figure preparation), and 
Adobe Illustrator CS6 (figure preparation).

\section{Materials and data availability}

Materials and data will be made available upon request.

\section{Acknowledgments}

We thank E. Garner (Harvard) and S. Lee (Newcastle) for providing strains/plasmids; E. Becker, L. Fellner, B. Herkenhoff-Hesselmann (Osnabrück), James Grimshaw, and Kenneth H. Seistrup (Newcastle) for aid in generating plasmids/strains; H. Winkelmann, H. Arlt for introducing MG into fluorescence microscopy, and C.P. Richter, T. Appelhans for technical discussions (Osnabrück). This work was supported by CRC944 (to GDH), 'Incentive Award' of the faculty of Biology/Chemistry of Osnabrück University (to GDH), and BBSRC New Investigator Award BB/S00257X/1 (to HS). MG is supported by a stipend of the Hans Mühlenhoff-Stiftung.

\section{Author Contributions}

Conceptualization, H.S., G.D-H.; Methodology, A.L., S.W., R.K., H.S., G.D-H.; Investigation, M.G., A.L., Z.B., H.S.; Writing - Original Draft, M.G., H.S., G.D-H.; Writing - Review \& Editing, H.S., G.DH.; Funding Acquisition, H.S., G.D-H.

\section{Declaration of Interests}

The authors declare no competing interests. 


\section{References}

Adams, D.W., and Errington, J. (2009). Bacterial cell division: assembly, maintenance and disassembly of the $\mathrm{Z}$ ring. Nat. Rev. Microbiol. 7, 642-653.

Altabe, S.G., Aguilar, P., Caballero, G.M., and de Mendoza, D. (2003). The Bacillus subtilis acyl lipid desaturase is a $\Delta 5$ desaturase. J. Bacteriol. 185, 3228-3231.

Aguilar, P.S., Cronan, J.E., Jr., and de Mendoza, D. (1998). A Bacillus subtilis gene induced by cold shock encodes a membrane phospholipid desaturase. J. Bacteriol. 180, 2194-2200.

Anagnostopoulos, C., and Spizizen, J. (1961). Requirements for transformation in Bacillus subtilis. J. Bacteriol. 81, 741-746.

Andersen, O.S., and Koeppe, R.E., II (2007). Bilayer thickness and membrane protein function: An energetic perspective. Annu. Rev. Biophys. Biomol. Struct. 36, 107-130.

Antonov, V.F., Petrov, V.V., Molnar, A.A., Predvoditelev, D.A., and Ivanov, A.S. (1980). The appearance of single-ion channels in unmodified lipid bilayer membranes at the phase transition temperature. Nature 283, 585-586.

Appelhans, T., Beinlich, F.R.M., Richter, C.P., Kurre, R., and Busch, K.B. (2018). Multi-color localization microscopy of single membrane proteins in organelles of live mammalian cells. J. Vis. Exp. 136, e57690.

Arnold, A., Wolf, H.U., Ackermann, B.P., and Bader, H. (1976). An automated continuous assay of membrane-bound and soluble ATPases and related enzymes. Anal. Biochem. 71, 209-213.

Barbe, V., Cruveiller, S., Kunst, F., Lenoble, P., Meurice, G., Sekowska, A., Vallenet, D., Wang, T., Moszer, I., Medigue, C., et al. (2009). From a consortium sequence to a unified sequence: the Bacillus subtilis 168 reference genome a decade later. Microbiology 155, 1758-1775.

Baumgart, T., Hammond, A.T., Sengupta, P., Hess, S.T., Holowka, D.A., Baird, B.A., and Webb, W.W. (2007). Large-scale fluid/fluid phase separation of proteins and lipids in giant plasma membrane vesicles. Proc. Natl. Acad. Sci. USA 104, 3165-3170.

Baumgart, T., Hess, S.T., and Webb, W.W. (2003). Imaging coexisting fluid domains in biomembrane models coupling curvature and line tension. Nature 425, 821-824.

Bigay, J., and Antonny, B. (2012). Curvature, lipid packing, and electrostatics of membrane organelles: Defining cellular territories in determining specificity. Dev. Cell 23, 886-895.

Blicher, A., Wodzinska, K., Fidorra, M., Winterhalter, M., and Heimburg, T. (2009). The temperature dependence of lipid membrane permeability, its quantized nature, and the influence of anesthetics. Biophys. J. 96, 4581-4591. 
Boudreaux, D.P., Eisenstadt, E., Iijima, T., and Freese, E. (1981). Biochemical and genetic characterization of an auxotroph of Bacillus subtilis altered in the acyl-CoA:acyl-carrier-protein transacylase. Eur. J. Biochem. 115, 175-181.

Bradley, E. (1981). Nonparametric estimates of standard error: The jackknife, the bootstrap and other methods. Biometrika 68, 589-599.

Brandt, K., Maiwald, S., Herkenhoff-Hesselmann, B., Gnirss, K., Greie, J.C., Dunn, S.D., and DeckersHebestreit, G. (2013). Individual interactions of the $b$ subunits within the stator of the Escherichia coli ATP synthase. J. Biol. Chem. 288, 24465-24479.

Budin, I., de Rond, T., Chen, Y., Chan, L.J.G., Petzold, C.J., and Keasling, J.D. (2018). Viscous control of cellular respiration by membrane lipid composition. Science 362, 1186-1189.

Burns, M., Wisser, K., Wu, J., Levental, I., and Veatch, S.L. (2017). Miscibility transition temperature scales with growth temperature in a zebrafish cell line. Biophys. J. 113, 1212-1222.

Chapman, D. (1975). Phase transitions and fluidity characteristics of lipids and cell membranes. Q. Rev. Biophys. 8, 185-235.

Chen, I.A., and Walde, P. (2010). From self-assembled vesicles to protocells. Cold Spring Harb. Perspect. Biol. 2, a002170.

Cordeiro, R.M. (2018). Molecular structure and permeability at the interface between phase-separated membrane domains. J. Phys. Chem. B 122, 6954-6965.

Cronan, J.E., Jr., and Gelmann, E.P. (1973). An estimate of the minimum amount of unsaturated fatty acid required for growth of Escherichia coli. J. Biol. Chem. 248, 1188-1195.

Cronan, J.E., Jr., Silbert, D.F., and Wulff, D.L. (1972). Mapping of the fabA locus for unsaturated fatty acid biosynthesis in Escherichia coli. J. Bacteriol. 112, 206-211.

Cybulski, L.E., Martin, M., Mansilla, M.C., Fernández, A., and de Mendoza, D. (2010). Membrane thickness cue for cold sensing in a bacterium. Curr. Biol. 20, 1539-1544.

Datsenko, K.A., and Wanner, B.L. (2000). One-step inactivation of chromosomal genes in Escherichia coli K-12 using PCR products. Proc. Natl. Acad. Sci. USA 97, 6640-6645.

Daugelavicius, R., Bakiene, E., and Bamford, D.H. (2000). Stages of polymyxin B interaction with the Escherichia coli cell envelope. Antimicrob. Agents Chemother. 44, 2969-2978.

de Jong, I.G., Beilharz, K., Kuipers, O.P., and Veening, J.W. (2011). Live cell imaging of Bacillus subtilis and Streptococcus pneumoniae using automated time-lapse microscopy. J. Vis. Exp. 53, e3145.

Debarbouille, M., Gardan, R., Arnaud, M., and Rapoport, G. (1999). Role of BkdR, a transcriptional activator of the SigL-dependent isoleucine and valine degradation pathway in Bacillus subtilis. J. Bacteriol. 181, 2059-2066. 
Deckers-Hebestreit, G., and Altendorf, K. (1992). Influence of subunit-specific antibodies on the activity of the $\mathrm{F}_{\mathrm{O}}$ complex of the ATP synthase of Escherichia coli. II. Effects of subunit $c$-specific polyclonal antibodies. J. Biol. Chem. 267, 12370-12374.

Diomandé, S.E., Nguyen-The, C., Guinebretière, M.H., Broussolle, V., and Brillard, J. (2015). Role of fatty acids in Bacillus environmental adaptation. Front. Microbiol. 6, 813.

Domański, J., Marrink, S.J., and Schafer, L.V. (2012). Transmembrane helices can induce domain formation in crowded model membranes. Biochim. Biophys. Acta 1818, 984-994.

Drin, G., and Antonny, B. (2010). Amphipathic helices and membrane curvature. FEBS Lett. 584, 18401847.

Drobnis, E.Z., Crowe, L.M., Berger, T., Anchordoguy, T.J., Overstreet, J.W., and Crowe, J.H. (1993). Cold shock damage is due to lipid phase transitions in cell membranes: A demonstration using sperm as a model. J. Exp. Zool 265, 432-437.

Düser, M.G., Bi, Y., Zarrabi, N., Dunn, S.D., and Börsch, M. (2008). The proton-translocating $a$ subunit of $\mathrm{F}_{\mathrm{O}} \mathrm{F}_{1}$-ATP synthase is allocated asymmetrically to the peripheral stalk. J. Biol. Chem. 283, 3360233610.

Elson, E.L., Fried, E., Dolbow, J.E., and Genin, G.M. (2010). Phase separation in biological membranes: Integration of theory and experiment. Annu. Rev. Biophys. 39, 207-226.

Ernst, R., Ballweg, S., and Levental, I. (2018). Cellular mechanisms of physicochemical membrane homeostasis. Curr. Op. Cell Biol. 53, 44-51.

Ernst, R., Ejsing, C.S., and Antonny, B. (2016). Homeoviscous adaptation and the regulation of membrane lipids. J. Mol. Biol. 428, 4776-4791.

Galli, E., and Gerdes, K. (2010). Spatial resolution of two bacterial cell division proteins: ZapA recruits ZapB to the inner face of the Z-ring. Mol. Microbiol. 76, 1514-1526.

Ghetler, Y., Yavin, S., Shalgi, R., and Arav, A. (2005). The effect of chilling on membrane lipid phase transition in human oocytes and zygotes. Hum. Reprod. 20, 3385-3389.

Gidden, J., Denson, J., Liyanage, R., Ivey, D.M., and Lay, J.O. (2009). Lipid compositions in Escherichia coli and Bacillus subtilis during growth as determined by MALDI-TOF and TOF/TOF mass spectrometry. Int. J. Mass Spectrom. 283, 178-184.

Hamoen, L.W., Smits, W.K., de Jong, A., Holsappel, S., and Kuipers, O.P. (2002). Improving the predictive value of the competence transcription factor (ComK) binding site in Bacillus subtilis using a genomic approach. Nucl. Acids Res. 30, 5517-5528.

Hachmann, A.B., Angert, E.R., and Helmann, J.D. (2009). Genetic analysis of factors affecting susceptibility of Bacillus subtilis to daptomycin. Antimicrob. Agents Chemother. 53, 1598-1609. 
Harayama, T., and Riezman, H. (2018). Understanding the diversity of membrane lipid composition.

Nat. Rev. Mol. Cell Biol. 19, 281-296.

Hazel, J.R. (1995). Thermal adaptation in biological membranes: Is homeoviscous adaptation the explanation? Annu. Rev. Physiol. 57, 19-42.

Heberle, F.A., and Feigenson, G.W. (2011). Phase separation in lipid membranes. Cold Spring Harb. Perspect. Biol. 3, a004630.

Heimburg, T. (2007). Thermal biophysics of membranes. (Weinheim: Wiley-VCH Verlag GmbH).

Heimburg, T. (2010). Lipid ion channels. Biophys. Chem. 150, 2-22.

Hilbers, F., Eggers, R., Pradela, K., Friedrich, K., Herkenhoff-Hesselmann, B., Becker, E., and DeckersHebestreit, G. (2013). Subunit $\delta$ is the key player for assembly of the $\mathrm{H}^{+}$-translocating unit of Escherichia coli $\mathrm{F}_{\mathrm{O}} \mathrm{F}_{1}$ ATP synthase. J. Biol. Chem. 288, 25880-25894.

Jäger, H., Birkenhäger, R., Stalz, W.D., Altendorf, K., Deckers-Hebestreit, G. (1998). Topology of subunit $a$ of the Escherichia coli ATP synthase. Eur. J. Biochem. 251, 122-132.

Jaqaman, K., Loerke, D., Mettlen, M., Kuwata, H., Gribstein, S., Schmid, S.L., Danuser, G. (2008). Robust single-particle tracking in live-cell time-lapse sequences. Nat. Methods 5, 695-702.

Junge W., and Nelson, N. (2015). ATP synthase. Annu. Rev. Biochem. 84, 631-657.

Kaneda, T. (1977). Fatty acids of the genus Bacillus: an example of branched-chain preference. Bacteriol Rev 41, 391-418.

Kelkar, D.A., and Chattopadhyay, A. (2007). The gramicidin ion channel: A model membrane protein. Biochim. Biophys. Acta 1768, 2011-2025.

Klein, W., Weber, M.H.W., and Marahiel, M.A. (1999). Cold shock response of Bacillus subtilis: Isoleucine-dependent switch in the fatty acid branching pattern for membrane adaptation to low temperatures. J. Bacteriol. 181, 5341-5349.

Köhler, P., Marahiel, M.A. (1997). Association of the histone-like protein HBsu with the nucleoid of Bacillus subtilis. J. Bacteriol. 179, 2060-2064.

Kosfeld, A., and Jahreis, K. (2012). Characterization of the interaction between the small regulatory peptide SgrT and the EIICBGlc of the glucose-phosphotransferase system of E. coli K-12. Metabolites 2, 756-774.

Lam, C., Hildebrandt, J., Schutze, E., and Wenzel, A.F. (1986). Membrane-disorganizing property of polymyxin B nonapeptide. J. Antimicrob. Chemother. 18, 9-15.

Lee, A.G. (2004). How lipids affect the activities of integral membrane proteins. Biochim. Biophys. Acta $1666,62-87$.

Lenaz, G. (1987). Lipid fluidity and membrane protein dynamics. Biosci. Rep. 7, 823-837. 
Lentz, B.R. (1993). Use of fluorescent probes to monitor molecular order and motions within liposome bilayers. Chem. Phys. Lipids 64, 99-116.

Letellier, L., Moudden, H., and Shechter, E. (1977). Lipid and protein segregation in Escherichia coli membrane: Morphological and structural study of different cytoplasmic membrane fractions. Proc. Natl. Acad. Sci. USA 74, 452-456.

Levental, K.R., Malmberg, E., Ernst, R., and Levental, I. (2018). Homeostatic remodeling of mammalian membranes in response to dietary lipid perturbations is essential for cellular fitness. BioRxiv, https://doi.org/10.1101/342873.

Lewis, P.J., and Marston, A.L. (1999). GFP vectors for controlled expression and dual labelling of protein fusions in Bacillus subtilis. Gene 227, 101-110.

Lewis, R.N.A.H., and McElhaney, R.N. (1985). Thermotropic phase behavior of model membranes composed of phosphatidylcholines containing iso-branched fatty acids. 1. Differential scanning calorimetric studies. Biochemistry 24, 2431-2439.

Lewis, R.N.A.H., Sykes, B.D., and McElhaney, R.N. (1987). Thermotropic phase behavior of model membranes composed of phosphatidylcholines containing dl-methyl anteisobranched fatty acids. 1 . Differential scanning calorimetric and ${ }^{31}$ P NMR spectroscopic studies. Biochemistry 26, 4036-4044.

Li, G.W., Burkhardt, D., Gross, C., and Weissman, J.S. (2014). Quantifying absolute protein synthesis rates reveals principles underlying allocation of cellular resources. Cell 157, 624-635.

Lingwood, D., and Simons, K. (2010). Lipid rafts as a membrane-organizing principle. Science 327, 4650.

Lorent, J.H., Diaz-Rohrer, B., Lin, X., Spring, K., Gorfe, A.A., Levental, K.R., and Levental, I. (2017). Structural determinants and functional consequences of protein affinity for membrane rafts. Nat. Commun. 8, 1219 .

Lucena, D., Mauri, M., Schmidt, F., Eckhardt, B., and Graumann, P.L. (2018). Microdomain formation is a general property of bacterial membrane proteins and induces heterogeneity of diffusion patterns. BMC Biol. 16, 97.

Mansilla, M.C., Cybulski, L.E., Albanesi, D., and de Mendoza, D. (2004). Control of membrane lipid fluidity by molecular thermosensors. J. Bacteriol. 186, 6681-6688.

Marr, A.G., and Ingraham, J.L. (1962). Effect of temperature on the composition of fatty acids in Escherichia coli. J. Bacteriol. 84, 1260-1267.

Mercier, R., Dominguez-Cuevas, P., and Errington, J. (2012). Crucial role for membrane fluidity in proliferation of primitive cells. Cell Rep. 1, 417-423. 
Morein, S., Andersson, A.S., Rilfors, A., and Lindblom, G. (1996). Wild-type Escherichia coli regulate the membrane lipid composition in a "window" between gel and non-lamellar structures. J. Biol. Chem. 271, 6801-6809.

Moriyama, Y., Iwamoto, A., Hanada, H., Maeda, M., and Futai, M. (1991). One-step purification of Escherichia coli $\mathrm{H}^{+}$-ATPase $\left(\mathrm{F}_{\mathrm{O}} \mathrm{F}_{1}\right)$ and its reconstitution into liposomes with neurotransmitter transporters. J. Biol. Chem. 266, 22141-22146.

Mostofian, B., Zhuang, T., Cheng, X., and Nickels, J.D. (2019). Branched-chain fatty acid content modulates structure, fluidity, and phase in model microbial cell membranes. J. Phys. Chem. B 123, 5814-5821.

Neidhardt, F.C., Ingraham, J.L., Schaechter, M. (1990). Physiology of the bacterial cell. A molecular approach. (Sunderland, MA, USA: Sinauer Associates).

Nguyen, C., Haushalter, R.W., Lee, D.J., Markwick, P.R., Bruegger, J., Caldara-Festin, G., Finzel, K., Jackson, D.R., Ishikawa, F., O'Dowd, B., et al. (2014). Trapping the dynamic acyl carrier protein in fatty acid biosynthesis. Nature 505, 427-431.

Nickels, J.D., Chatterjee, S., Mostofian, B., Stanley, C.B., Ohl, M., Zolnierczuk, P., Schulz, R., Myles, D.A.A., Standaert, R.F., Elkins J.G. et al. (2017). Bacillus subtilis lipid extract, a branched-chain fatty acid model membrane. J. Phys. Chem. Lett. 8, 4214-4217.

Nickels, J.D., Hogg, J., Cordner, D., and Katsaras, J. (2019). Lipid rafts in bacteria: Structure and function. In Health consequences of microbial interactions with hydrocarbons, oil, and lipids, $\mathrm{H}$. Goldfine (Cham: Springer Nature Switzerland AG), pp. 1-30.

Nicolson, G.L. (2014). The fluid-mosaic model of membrane structure: Still relevant to understanding the structure, function and dynamics of biological membranes after more than 40 years. Biochim. Biophys. Acta 1838, 1451-1466.

Papahadjopoulos, D., Jacobson, K., Nir, S., and Isac, T. (1973). Phase transitions in phospholipid vesicles. Fluorescence polarization and permeability measurements concerning the effect of temperature and cholesterol. Biochim. Biophys. Acta 311, 330-348.

Parasassi, T., De Stasio, G., d'Ubaldo, A., and Gratton, E. (1990). Phase fluctuation in phospholipid membranes revealed by Laurdan fluorescence. Biophys. J. 57, 1179-1186.

Parsons, J.B., and Rock, C.O. (2013). Bacterial lipids: Metabolism and membrane homeostasis. Prog. Lipid Res. 52, 249-276.

Picas, L., Carreterro-Genevrier, A., Montero, M.T., Vázquez-Ibar, J. L., Seantier, B., Milhiet, P. E., and Hernández-Borrell, J. (2010). Preferential insertion of lactose permease in phospholipid domains: AFM observations. Biochim. Biophys. Acta 1798, 1014-1019.

Pilizota, T., and Shaevitz, J.W. (2012). Fast, multiphase volume adaptation to hyperosmotic shock by Escherichia coli. Plos One 7, e35205. 
Ramadurai, S., Holt, A., Krasnikov, V., van den Bogaart, G., Killian, J.A., and Poolman, B. (2009). Lateral diffusion of membrane proteins. J. Am. Chem. Soc. 131, 12650-12656.

Renz, A., Renz, M., Klütsch, D., Deckers-Hebestreit, G., and Börsch, M. (2015). 3D-localization microscopy and tracking of $\mathrm{F}_{\mathrm{O}} \mathrm{F}_{1}$-ATP synthases in living bacteria. Proc. SPIE 9331, 93310D.

Richter, D., Moraga, I., Winkelmann, H., Birkholz, O., Wilmes, S., Schulte, M., Kraich, M., Kenneweg, H., Beutel, O., Selenschik, P., et al. (2017). Ligand-induced type II interleukin-4 receptor dimers are sustained by rapid re-association within plasma membrane microcompartments. Nat. Commun. 8 , 15976.

Rickenberg, H.V., and Lester, G., (1955). The preferential dsyntheis of $\beta$-galactosidase in Escherichia coli. J. Gen. Microbiol. 13, 279-284.

Ridder, A.N.J.A., Spelbrink, R.E.J., Demmers, J.A.A., Rijkers, D.T.S., Liskamp, R.M.J., Brunner, J., Heck, A.J.R., de Kruijff, B., and Killian, J.A. (2004). Photo-crosslinking analysis of preferential interactions between a transmembrane peptide and matching lipids. Biochemistry 43, 4482-4489.

Rossignol, M., Thomas, P., and Grignon, C. (1982). Proton permeability of liposomes from natural phospholipid mixtures. Biochim. Biophys. Acta 684, 195-199.

Roth, B.L., Poot, M., Yue, S.T., and Millard, P.J. (1997). Bacterial viability and antibiotic susceptibility testing with SYTOX green nucleic acid stain. Appl. Environ. Microbiol. 63, 2421-2431.

Rudner, D.Z., Pan, Q., and Losick, R.M. (2002). Evidence that subcellular localization of a bacterial membrane protein is achieved by diffusion and capture. Proc. Natl. Acad. Sci. USA 99, 8701-8706.

Sambrook, J., Fritsch, E.F., Maniatis, T. (1989). Molecular cloning: A laboratory manual, 2nd Edition. (Cold Spring Harbor, NY, USA: Cold Spring Harbor Laboratory Press).

Sasser, M. (1990). Identification of bacteria through fatty acid analysis. In Methods in phytobacteriology, Z. Klement, K. Rudolph, D.C. Sands, eds. (Budapest, Hungary: Akadémiai Kiadó).

Schäfer, L.V., de Jong, D.H., Holt, A., Rzepiela, A.J., de Vries, A.H., Poolman, B., Killian, J.A., and Marrink, S.J. (2011). Lipid packing drives the segregation of transmembrane helices into disordered lipid domains in model membranes. Proc. Natl. Acad. Sci. USA 108, 1343-1348.

Schägger, H., von Jagow, G. (1987). Tricine-sodium dodecyl sulfate polyacrylamide gel electrophoresis for the separation of proteins in the range of 1 to $100 \mathrm{kDa}$. Anal. Biochem. 166, 368-379.

Scheinpflug, K., Krylova, O., and Strahl, H. (2017a). Measurement of cell membrane fluidity by Laurdan GP: Fluorescence spectroscopy and microscopy. Methods Mol. Biol. 1520, 159-174.

Scheinpflug, K., Wenzel, M., Krylova, O., Bandow, J.E., Dathe, M., and Strahl, H. (2017b). Antimicrobial peptide cWFW kills by combining lipid phase separation with autolysis. Sci. Rep. 7, 44332.

Schindelin, J., Arganda-Carreras, I., Frise, E., Kaynig, V., Longair, M., Pietzsch, T., Preibisch, S., 
Rueden, C., Saalfeld, S., Schmid, B., et al. (2012). Fiji: an open-source platform for biological-image analysis. Nat. Methods 9, 676-682.

Schmid, F. (2017). Physical mechanisms of micro- and nanodomain formation in multicomponent lipid membranes. Biochim. Biophys. Acta 1859, 509-528.

Sergé, A., Bertaux, N., Rigneault, H., and Marguet, D. (2008). Dynamic multiple-target tracing to probe spatiotemporal cartography of cell membranes. Nat. Methods 5, 687-694.

Sharp, M.D., and Pogliano, K. (1999). An in vivo membrane fusion assay implicates SpoIIIE in the final stages of engulfment during Bacillus subtilis sporulation. Proc. Natl. Acad. Sci. USA 96, 1455314558.

Shaner, N.C., Lambert, G.G., Chammas, A., Ni, Y., Cranfill, P.J., Baird, M.A., Sell, B.R., Allen, J.R., Day, R.N., Israelsson, M., et al. (2013). A bright monomeric green fluorescent protein derived from Branchiostoma lanceolatum. Nat. Methods 10, 407-409.

Shi, H., Bratton, B.P., Gitai, Z., and Huang, K.C. (2018). How to build a bacterial cell: MreB as the foreman of E. coli construction. Cell 172, 1294-1305.

Silhavy, T.J., Kahne, D., and Walker, S. (2010). The bacterial cell envelope. Cold Spring Harb. Perspect. Biol. 2, a000414.

Sinensky, M. (1974). Homeoviscous adaptation - a homeostatic process that regulates the viscosity of membrane lipids in Escherichia coli. Proc. Natl. Acad. Sci. USA 71, 522-525.

Stokes, N.R., Sievers, J., Barker, S., Bennett, J.M., Brown, D.R., Collins, I., Errington, V.M., Foulger, D., Hall, M., Halsey, R., et al. (2005). Novel inhibitors of bacterial cytokinesis identified by a cellbased antibiotic screening assay. J. Biol. Chem. 280, 39709-39715.

Strahl, H., and Errington, J. (2017). Bacterial membranes: Structure, domains, and function. Annu. Rev. Microbiol. 71, 519-538.

Strahl, H., and Hamoen, L.W. (2010). Membrane potential is important for bacterial cell division. Proc. Natl. Acad. Sci. USA 107, 12281-12286.

Strahl, H., Burmann, F., and Hamoen, L.W. (2014). The actin homologue MreB organizes the bacterial cell membrane. Nat. Commun. 5, 3442.

Suárez-Germà, C., Montero, M.T., Ignés-Mullol, J., Hernández-Borrell, J., and Domènech, Ò. (2011). Acyl chain differences in phosphatidylethanolamine determine domain formation and LacY Distribution in biomimetic model membranes. J. Phys. Chem. B 115, 12778-12784.

Suckau, D., Resemann, A., Schuerenberg, M., Hufnagel, P., Franzen, J., and Holle, A. (2003). A novel MALDI LIFT-TOF/TOF mass spectrometer for proteomics. Anal. Bioanal. Chem. 376, 952-965.

Suutari, M., and Laakso, S. (1992). Unsaturated and branched chain-fatty acids in temperature adaptation of Bacillus subtilis and Bacillus megaterium. Biochim. Biophys. Acta 1126, 119-124. 
Te Winkel, J.D., Gray, D.A., Seistrup, K.H., Hamoen, L.W., and Strahl, H. (2016). Analysis of antimicrobial-triggered membrane depolarization using voltage sensitive dyes. Front. Cell Dev. Biol. $4,29$.

Thomason, L.C., Costantino, N., and Court, D.L. (2007). E. coli genome manipulation by P1 transduction. Curr. Protoc. Mol. Biol. Chapter 1, Unit 117.

Torres M.J., Kew, K.A., Ryan, T.E., Pennington, E.R., Lin, C.T., Buddo, K.A., Fix, A.M., Smith, C.A., Gilliam, L.A., Karvinen, S. et al. (2018). 17 $\beta$-Estradiol directly lowers mitochondrial memebrane microviscosity and improves bioenergetic function in skeletal muscle. Cell Metab. 27, 167-179.

Typas, A., Banzhaf, M., Gross, C.A., and Vollmer, W. (2012). From the regulation of peptidoglycan synthesis to bacterial growth and morphology. Nat. Rev. Microbiol. 10, 123-136.

Ursell, T.S., Nguyen, J., Monds, R.D., Colavin, A., Billings, G., Ouzounov, N., Gitai, Z., Shaevitz, J.W., and Huang, K.C. (2014). Rod-like bacterial shape is maintained by feedback between cell curvature and cytoskeletal localization. Proc. Natl. Acad. Sci. USA 111, E1025-1034.

Valentine, D.L. (2007). Adaptations to energy stress dictate the ecology and evolution of the Archaea. Nat. Rev. Microbiol. 5, 316-323.

van de Vossenberg, J.L.C.M., Driessen, A.J.M., da Costa, M.S., and Konings, W.N. (1999). Homeostasis of the membrane proton permeability in Bacillus subtilis grown at different temperatures. Biochim. Biophys. Acta 1419, 97-104.

Veatch, S.L. (2007). From small fluctuations to large-scale phase separation: Lateral organization in model membranes containing cholesterol. Semin. Cell Dev. Biol. 18, 573-582.

Veatch, S.L., and Keller, S.L. (2002). Organization in lipid membranes containing cholesterol. Phys. Rev. Lett. 89, 268101.

Wenzel, M., Vischer, N.O.E., Strahl, H., and Hamoen, L.W. (2018). Assessing membrane fluidity and visualizing fluid membrane domains in bacteria using fluorescent membrane dyes. Bio-protocol 8 , e3063.

Wiedemann, I., Benz, R., and Sahl, H.G. (2004). Lipid II-mediated pore formation by the peptide antibiotic nisin: a black lipid membrane study. J. Bacteriol. 186, 3259-3261.

Willecke, K., and Pardee, A.B. (1971). Fatty acid-requiring mutant of Bacillus subtilis defective in branched chain $\alpha$-keto acid dehydrogenase. J. Biol. Chem. 246, 5264-5272.

Yang, X., Lyu, Z., Miguel, A., McQuillen, R., Huang, K.C., and Xiao, J. (2017). GTPase activitycoupled treadmilling of the bacterial tubulin FtsZ organizes septal cell wall synthesis. Science 355, 744-747.

Zhu, K., Zhang, Y.M., and Rock, C.O. (2009). Transcriptional regulation of membrane lipid homeostasis in Escherichia coli. J. Biol. Chem. 284, 34880-34888. 